\title{
Economic Development and the Escape from High Mortality
}

\author{
JAVIER A. BIRCHENALL * \\ University of California, Santa Barbara, CA, USA
}

\begin{abstract}
Summary. - This paper studies the characteristic features of the escape from high mortality as recorded from the historical experience of Northwestern Europe and from the current experience of less developed countries. The paper documents stylized facts of mortality change and measures the contribution of economic development, represented by income per capita, to the mortality decline during the second half of the 20th century. The paper argues that improvements in economic conditions since the 18th century are an important factor behind the decline in death rates in developed countries and in the subsequent reduction of death rates in less developed countries. We show that economic development lowers mortality through differential effects in infectious disease mortality and that quantitatively, income growth is able to account for between one-third and one-half of the recent mortality decline.
\end{abstract}

(c) 2007 Elsevier Ltd. All rights reserved.

JEL classification - $\mathrm{I} 12, \mathrm{O} 11, \mathrm{O} 33$

Key words - mortality, economic development, developed and less developed countries

\section{INTRODUCTION}

Death is inevitable and irreversible, but the last three centuries have seen remarkable progress in the reduction of human mortality. The mortality of pre-modern populations varied considerably, but a simple comparison typically finds that the average life expectancy at birth has roughly doubled during the last three centuries. The decline in death rates has proceeded at non-uniform rates, but it has affected all geographic areas and all demographic groups in the world. Today, even the countries with the highest death rates, such as those in sub-Saharan Africa, are above the historical mean despite the HIV/AIDS epidemic that has reduced the life expectancy at birth of their inhabitants by at least 10 years.

The list of explanations offered as to why mortality has declined is not a short one, and a comprehensive analysis is likely to suggest multiple factors and mutual reinforcements. The spectacular mortality decline in less developed countries during the second half of the 20 th century has generated the impression that the mortality decline was simply due to modern medicine and innovations in medical science.
However, most of the explanations based on modern medicine could not have played a large role in the mortality decline of developed countries, since the fundamental innovations that served to control the spread of infectious disease originated when the mortality decline was already in progress (McKeown, 1976). Of the major breakthroughs in disease control listed in Easterlin (2004, Tables 7.1-7.2), only vaccinations against smallpox took place before the mid-19th century. ${ }^{1}$

Public health efforts through sanitation and measures directed to lower the exposure to infectious diseases played an important role in the acceleration of the mortality decline of developed countries since the last quarter of the 19th century (i.e., Cutler \& Miller, 2005)

\footnotetext{
* This paper is based on my dissertation research. I am especially indebted to Professor Robert Fogel for many valuable suggestions. I have also benefited from comments by seminar participants at numerous locations and from detailed suggestions from three anonymous reviewers of this Journal. Financial support from Banco de la República Colombia is gratefully acknowledged. Final revision accepted: June 13, 2006.
} 
and in the escape from high mortality in less developed countries, but these efforts mainly benefited urban populations at first. Prior to the public health intervention in cities, rural areas of Northwestern Europe and North America achieved sustained reductions in mortality from infectious diseases sensitive to nutritional status. Attention has turned, once again, to economic development as a factor in the escape from high mortality. ${ }^{2}$

Empirical evidence supports the idea that improvements in economic conditions in the 18 th century were fundamental in the decline in death rates in developed countries and an important factor in the subsequent reduction of death rates in less developed countries. Fogel (1994, and elsewhere) shows how improvements in food availability and nutritional status translate into lower mortality risks by improvements in body composition. As he points out, well-nourished and healthy children develop better cells and organs and reach higher heights and lower mortality. In the secular decline, Fogel (1994) argues, nutrition and factors associated with body composition explain most of the actual mortality decline prior to 1870 and half of it after 1870 .

For less developed countries, Preston (1980) has shown that economic development, measured by higher income per capita, is able to explain about $30 \%$ of the modern increase in life expectancy during 1940-70. Although Preston (1975) showed that economic development could only account for as much as $30 \%$ of the mortality improvements in the world from the 1930 s to the $1960 \mathrm{~s}$, aggregate income gains were the dominating factor in explaining mortality decline during 1960s-70s (Preston, 1985). Similar quantitative effects were found by Pritchett and Summers (1996) and Easterly (1999) through instrumental variables (IV) estimation rather than through the OLS estimates employed by Preston (1975, 1980, 1985).

The role of economic development and changes in public health (broadly defined) as the fundamental aspects in low mortality leave little or no room for additional explanations. Some, based on genetic factors, either in humans or in the pathogens responsible for high mortality, are available, but they seem rather unlikely (although a decline in virulence appears to have affected scarlet fever, see McKeown, 1976). Kunitz (1983) argues convincingly against genetic change in the pathogens responsible for high mortality since virulence is still high in many poor countries. In addition, the change in mortality during the last three centuries has been so fast and so widely distributed that genetic changes in humans are incompatible with such mortality trends. ${ }^{3}$

In this paper, we study the characteristic features of the escape from high mortality as recorded from the historical experience of Northwestern Europe and from the current experience of less developed countries. Based on historical and current evidence, we document the basic facts of mortality change. We show that the mortality transition has striking similarities in terms of the demographic groups mostly benefitting from the decline and the geographic areas that were first affected by low mortality. The changes have important implications for recent theoretical attempts to study modern population and economic changes and for the ongoing debate on the role of economic factors in the mortality decline.

The second objective of the paper is to measure the contribution of economic development, represented by income per capita, to the mortality decline in the second half of the 20th century. Using aggregate measures of mortality, we are able to avoid many of the difficulties inherent in individual estimates but face other statistical problems such as endogeneity. Economic development is likely to reduce mortality and morbidity even by simple Malthusian channels, but there is no doubt that the reduction in mortality has translated into higher income per capita. Consequently, OLS estimates of the effects of income on mortality are likely to provide a biased measure of the effect of economic development in the escape from high mortality.

To obtain estimates of the effect of income on mortality rates that are not affected by the presence of endogeneity, we rely on IV constructed from economic variables and residuals. As the validity of instruments often employed in the economic growth literature (i.e., Easterly, 1999; Pritchett \& Summers, 1996) is not unproblematic, we also rely on the dynamic structure of the model using dynamic panel estimators, that is, Arellano and Bond (1991) and Blundell and Bond (1998).

In contrast to previous aggregate estimates, we employ information from different causes of death from the World Health Organization Statistical Information System (WHOSIS). This data set provides new insights to the patterns of mortality, but these data have not been systematically analyzed (with the exception of Becker, Philipson, \& Soares, 2005). In the 
paper, we find that income growth contributed to the world mortality decline during 1960-90 in non-trivial amounts and that the contribution has not decreased over time as a pure technology transfer would suggest. The contribution of economic development largely varies by cause of death, but, as expected from the epidemiological literature, the contribution of economic development to diseases sensitive to nutrition, $45 \%$, is larger than to diseases in which nutrition has a minimal influence, $25 \%$.

Due to the undisputable importance in the decline in mortality, we center our attention on the reduction in infectious diseases as causes of death in less developed countries. ${ }^{4}$ The paper argues that improvements in economic conditions since the 18th century are an important factor behind the initial decline in death rates in developed countries and in the subsequent reduction of death rates in less developed countries. However, as the epidemiological literature suggests, economic development lowers mortality rates through differential effects in infectious disease mortality.

The rest of the paper proceeds as follows: Section 2 constructs the stylized facts behind the escape from high mortality for developed countries and summarizes the available evidence on the different forces that contributed to the mortality decline. Section 3 considers the case of less developed countries. Due to similarities, most of the analysis of Section 2 follows through for less developed countries as well, although the important differences are highlighted. Section 4 describes the data and the econometric methods to measure the contribution of economic growth to the world mortality decline during 1960-90 using different causes of death. Section 5 presents the results of the estimation and the estimated contribution of income growth. Section 6 concludes.

\section{MORTALITY SINCE MALTHUS}

High mortality represented one of the most persistent barriers to population growth and economic development in pre-modern economies. Historically, the European population faced life expectancies at birth that never seem to have exceeded 40 years and suffered several declines due to famines and recurrent epidemics (Wrigley \& Schofield, 1981). At a point between the 17 th and 18 th centuries, mortality started to decline and income and population started to increase, contradicting the Malthusian hypoth- esis in which both should have been negatively related.

The simultaneous rise of per capita income and population provides important facts for an economic analysis of mortality. It does not seem as a random event that mortality declined first among the countries that first experienced the benefits from per capita income growth and that less developed countries always experience lower life expectancies than developed countries (we will return to this point below). However, it is not obvious that income growth in developed countries increased life expectancy at birth directly because urbanization, a consequence of economic development, slowed down the mortality decline of Northwestern Europe and North America since cities had relatively higher mortality schedules than rural areas (e.g., Fogel, Engerman, Trussell, Floud, \& Pope, 1978; Woods, 2000, 2003).

The association between higher per capita income and higher life expectancy in Northwestern Europe and North America can be better understood as part of a structural transformation in which technological change in agriculture sustains economic growth in nonagricultural sectors but leads to a deterioration in mortality due to urbanization. Since food is an income inelastic good, as agriculture becomes more productive, less labor is required in food production and more labor can be released to more productive activities. At the same time, higher agricultural productivity improves nutrition, lowers susceptibility to infectious diseases, and consequently increases life expectancy and population growth whenever the effects of urbanization do not fully offset the gains in agricultural productivity.

Although these Malthusian mechanics appear very simple to account for the current state of population and the escape from the Malthusian world, the next sections provide an empirical basis that favors the economic conditions outlined above as the main factors in the escape from high mortality.

\section{(a) Facts and implications}

By the middle of the 20th century, Northwestern Europe and North America had achieved a new pattern of mortality in which infectious diseases were substituted by chronic and degenerative conditions as the main causes of death, and the modal age of death shifted from childhood to older ages. The timing and geographical distribution of the decline in 
mortality across Northwestern Europe varied, but historical statistics have revealed that England was the first country to escape from high mortality at the time Malthus published his Essay on the Principle of Population (Malthus, 1803). ${ }^{5}$

Figures from Wrigley and Schofield (1981) and Wrigley, Davis, Oeppen, and Schofield (1997), and complementary sources show that the secular decline in mortality in England and Wales took place in two waves. The first wave started around 1750 and lasted until 1820 , after which mortality stabilized for half a century. ${ }^{6}$ The second wave began around 1870 and has not yet ended because mortality at older ages is still declining (e.g., Oeppen \& Vaupel, 2002).

Since historical sources provide enough information for a broad interpretation of the mortality decline, we propose the following stylized facts:

(a) The initial decline in mortality is due to reductions in death rates at early ages and not to sustained increases in the life span of older-age populations.

(b) The initial mortality reduction primarily benefited rural areas. Urban mortality remained high due to the urbanization associated with the Industrial Revolution.

(c) Although mortality rates fluctuated more before the mid-18th century, the elimination of crisis mortality accounts for only a small fraction of the secular decline in mortality.

(a) That mortality at early ages contributed most to the reductions in mortality follows from the observed changes in life expectancy and age-specific death rates. Before 1750, infant and child mortalities were very high and had a considerable impact on life expectancy at birth and overall mortality (Vallin, 1991). To determine the overall mortality reduction, Table 1 computes relative death probabilities (conditional on surviving to the beginning of every age range) for England and Wales with respect to a base set in 1750 . The table brings out the pre-transition situation clearly. Almost 20\% of the babies born failed to survive until their first birthday, and around one-third died before the age of 5. During the first year of life, the probability of death was about six times the level found among children 10-14 years old and about three times the level of children 5-9 years old.

Before the mid-20th century, increases in life expectancy in developed countries were obtained by a reduction in the number of people dying in early life and not by changes in life expectancy at older ages. Although the initial decline that started during 1700-50 was partially reversed during $1800-60$, by 1900 mortality before the age of 10 declined by about $40 \%$ while old age mortality remained unchanged. Up to 1960 , mortality between the ages of 60 and 64 fell by $10 \%$, whereas in 1960, the probability of dying at age 5 was less than $5 \%$ of the value in 1700 (see Table 1). ${ }^{7}$

Several implications follow from the fact that early life had a predominant role in the mortality decline. A complementarity between longevity and human capital investments has been long recognized and studied (Kalemli-Ozcan, Ryder, \& Weil, 2000; Meltzer, 1992): higher human capital creates an incentive for a longer life span (in order to increase the time to collect the benefits of the investment) and a longer life span is an incentive for more human capital accumulation. However, a direct incentive in terms of life span is not clearly arguable since gains in old age mortality are secondary to infant and

Table 1. Relative age-specific death rates (per thousand)

\begin{tabular}{lccccccccc}
\hline & \multicolumn{1}{c}{ Age } & & \\
\cline { 3 - 9 } & & 0 & $1-4$ & $5-9$ & $10-14$ & $30-34$ & $40-44$ & $60-64$ & $70-74$ \\
\hline Death rates & & 170.4 & 107.3 & 41.1 & 25.7 & 48.2 & 78.1 & 171.6 & 341.1 \\
Relative death rates $(1750=100)$ & 1750 & 100 & 100 & 100 & 100 & 100 & 100 & 100 & 100 \\
& & & & & & & & & \\
& 1800 & 85 & 91 & 63 & 78 & 88 & 73 & 93 & 122 \\
& 1860 & 88 & 131 & 101 & 95 & 106 & 84 & 134 & 184 \\
& 1900 & 86 & 71 & 45 & 42 & 63 & 65 & 132 & 125 \\
& 1930 & 37 & 23 & 26 & 27 & 34 & 35 & 105 & 121 \\
& 1960 & 13 & 3 & 5 & 6 & 11 & 17 & 89 & 102 \\
\hline
\end{tabular}

England and Wales, 1750-1960.

Source: Wrigley et al. (1997, Tables 6.14 and 6.19) and Case et al. (1962). 
child mortality. In fact, a large part of the gains in mortality took place before children could engage in formal education (see Table 1). ${ }^{8}$ Also, education and human capital accumulation often provide the means for a faster and more effective spread of infectious diseases for children (see, e.g., Miguel \& Kremer, 2004).

It has also been shown that the scope of changes in childhood nutrition and exposure to disease (as early as in utero) extends well beyond the improvement of child mortality and into health in later life. As the survey of Elo and Preston (1992) shows (also Mosley \& Gray, 1993), some changes in adult and old-age mortality can be traced back to conditions experienced early in life. If correct, the idea that early life conditions have long-lasting consequences for adult and old age mortality is an indication that a life-cycle approach to mortality is needed to fully evaluate the effect of economic and social changes experienced by children. It would also imply that the large gains in old-age mortality in the second half of the 20th century have been in part the consequence of changes experienced by cohorts born during the early part of the 20th century.

(b) From antiquity to the early 20th century, urban areas experienced higher mortality than rural areas did. Table 2 presents age-specific death rates for London and England and Wales excluding London. As the table shows, mortality rates in London were more than double the mortality rates in England and Wales. Szreter and Mooney (1998) further demonstrate the extent to which rapid urbanization and rapid city growth created a penalty in England. For example, Szreter and Mooney (1998) show that children born in Manchester in 1841 had a life expectancy of 25.3 years, which was 16.4 years lower than the average life expectancy in England and Wales and 19.8 years lower than in rural areas. ${ }^{9}$
The presence of an urban penalty has been widely documented. Scheidel (1994) corroborates that ancient Rome, the largest city of pre-modern Europe, depended on a constant influx of immigrants to compensate for the effects of high mortality due to infectious diseases. In modern times, cities in Northwestern Europe and North America also displayed a substantial penalty in mortality. Parish records for Finland show marked regional differences in mortality (Turpeinen, 1978). France and Sweden exhibit a penalty, as Preston and Van de Walle (1978) and Hedenborg (2000) show. Life expectancy in Paris (Seine) in the 19th century was 30.8 years compared to a value of 38.7 years for overall France. Compared to Europe, the early 19th-century United States was quite rural and presented relatively low death rates, as Malthus (1803) himself remarked. For the urban US white population, life expectancy at birth was 46 years, while it was 55 years for the rural white population (Haines, 2001). Moreover, cities with populations of more than 50,000 in 1830 (Boston, New York, and Philadelphia) had death rates more than twice as high as the death rates of rural areas (Fogel et al., 1978).

In developed countries, the urban differential in mortality remained positive until the first decades of the 20th century; generalized reversals were not observed until after the First World War (Easterlin, 2004, Figure 7.1).

The relation between urbanization and mortality seems in part responsible for the negative association between rapid economic growth and mortality throughout industrialization. Adult life expectancy in the United States declined and adult males became $2 \mathrm{~cm}$ shorter within a generation prior to the Civil War when per capita income increased at an annual rate of $1.4 \%$ (Fogel et al., 1978). ${ }^{10}$ Similar reversals have been documented for continental Europe

Table 2. Urban-rural age-specific death rates (per thousand)

\begin{tabular}{|c|c|c|c|c|c|c|c|c|c|}
\hline \multirow[b]{2}{*}{ Age } & \multicolumn{3}{|c|}{$1650-99$} & \multicolumn{3}{|c|}{$1700-49$} & \multicolumn{3}{|c|}{$1750-99$} \\
\hline & 0 & $1-4$ & $5-9$ & 0 & $1-4$ & $5-9$ & 0 & $1-4$ & $5-9$ \\
\hline England and Wales & 179 & 109 & 27 & 196 & 114 & 28 & 168 & 108 & 24 \\
\hline England and Wales (except London) & 170 & 95 & 23 & 177 & 91 & 19 & 154 & 88 & 20 \\
\hline London & 260 & 244 & 67 & 342 & 298 & 95 & 276 & 253 & 57 \\
\hline Ratio & 1.53 & 2.56 & 2.98 & 1.93 & 3.29 & 4.93 & 1.79 & 2.86 & 2.87 \\
\hline
\end{tabular}

Note: Age-specific death rates for England and Wales, and London from Wrigley et al. (1997, Table 6.14) and Landers (1992, Table 3), respectively. To compute the rates of England and Wales (without London), we employ London's share of population from Wrigley (1987, p. 162). 
and Scandinavia, although certain sub-populations in the United States failed to experience a reduction in physical stature with industrialization (populations from the urban middle class such as the cadets at West Point Military Academy as well as slave men but not free slaves, see Komlos \& Baten, 2004 for a recent overview). These exceptions, as Komlos (1998) points out, suggest that causes other than a deterioration in the epidemiological environment alone played a role in the decline of height associated with the onset of modern economic growth (we will return to the analysis of urbanization and height below).

(c) Only through the large national samples of Wrigley and Schofield (1981) was it possible to assess the effect of mortality crises on total mortality because analyses of local areas overemphasized the role of crises as they were geographically concentrated. Wrigley and Schofield (1981) (also Fogel, 1992) have shown that death rates declined in England and Wales because of reductions in normal mortality and not because of the eradication of famines or mortality crises. ${ }^{11}$ Since most crises were confined to peripheral areas, they had a small aggregate impact (with obvious exceptions ${ }^{12}$ ), and their attenuation explains only a small fraction of the mortality decline. For example, although mortality crises started to decline as early as the 17 th century, removing crises from crude death rates (CDR) indicates that the crises' contribution to the overall decline in England and Wales is less than $10 \%$ (Table 3 ).

\section{(b) Understanding high mortality}

Infectious diseases caused high mortality in pre-modern economies because the general population was both highly susceptible and frequently exposed to infectious agents. Chronic malnutrition is particularly important for understanding high mortality because nutritional deficiencies increase the susceptibility to infection as well as the prevalence and severity of infectious diseases.

Malnutrition is caused by inadequate intakes or excessive energy claims on an otherwise adequate diet, but a separate contribution of each factor is difficult to measure even under controlled experiments (see Scrimshaw, Taylor, \& Gordon, 1968 for a classical study of nutrition interventions aimed at mothers and children in a developing country). Yet, estimates of nutrient intakes suggest energy intakes below 2,000 kcals per day in pre-industrial England and Wales with improvements in the quantity and quality of the English diet taking place since the mid-18th century. ${ }^{13}$ Associated with such improvement lies the most acceptable explanation for the initial decline in mortality: improved nutrition. The grounds for that conclusion are twofold:

(d) Anthropometric measures with a high predictive value for mortality accurately predict a mortality decline for cohorts born in the 18 th century.

(e) Prior to any public health intervention or medical innovation, diseases sensitive to nutritional status and adequate nursing started to decline.

Higher food availability was essential for the initial mortality decline, but the analysis of urban-rural differences in mortality shows that public health efforts eventually controlled the high levels of exposure to infectious diseases in cities and eliminated the urban penalty during the 20th century.

(f) Public health measures, beginning in the late 19th century, reversed the urban penalty (mainly by the reduction in water and foodborne infections).

(d) High infection rates, as both a consequence and a cause of malnutrition, compromise energy available for cellular growth and provide evidence to assess changes in mortality through anthropometric measures. As Fogel (1994) shows, with the use of a Waaler surface

Table 3. Impact of mortality crises in England and Wales, 1541-1871

\begin{tabular}{lcccc}
\hline & CDR & Crisis CDR & Normal CDR & Percent contribution of crisis \\
\hline $1541-1600$ & 26.93 & 1.87 & 25.06 & 6.94 \\
$1601-1700$ & 27.33 & 1.57 & 25.76 & 5.74 \\
$1701-50$ & 29.18 & 1.20 & 27.98 & 4.11 \\
$1751-1800$ & 27.07 & 0.48 & 26.59 & 1.76 \\
$1801-50$ & 23.99 & 0.14 & 23.85 & 0.58 \\
$1851-71$ & 22.42 & 0.13 & 22.29 & 0.58 \\
\hline
\end{tabular}

Source: Fogel (1992, Table 4). 
(an iso-mortality risk surface), the historical changes in height, weight, and BMI in England and Wales can be used to measure the role of nutritional gains for the overall decline in mortality. According to Fogel's (1994) calculations, nutritional gains explain $90 \%$ of the decline up to 1870 and $50 \%$ after 1870 .

As with changes in life expectancy, pre-modern populations experienced cycles of various durations in physical stature rather than a single structural break. In modern data, heights in England and Wales reached their lowest point during the 17 th century and experienced a recovery after the first quarter of the 18 th century with a decline decades after (there is some disagreement over the exact dates because there was a temporary improvement in the 1820 s, see Floud et al., 1990; Komlos, 1993; Komlos \& Baten, 2004). For example, Komlos (2006, p. 4) convincingly argues that the initial trends in Floud et al. (1990) "were not identified accurately" and suggests, for lower-class English boys, that "heights declined between the birth cohorts of circa 1770 and those of 1795 , increased thereafter, and then declined again in the 1830 s and 1840s."

But the cycles in height are not just a modern feature, because physical stature varied considerably over long periods of time. For instance, heights in Europe reached their highest point in the Middle Ages (in the fifth and sixth centuries, according to Köepke \& Baten, 2005) with levels that exceeded physical stature even in 1850 (see Köepke \& Baten, 2005; Steckel, 2005a for European analyses, and Steckel, $2005 \mathrm{~b}$ for pre-Columbian populations). Overall, in an analysis of more than 9,000 sets of human remains, Köepke and Baten (2005) show that no long-term trend exists for heights between the first century and the beginning of the Industrial Revolution. Still, as Köepke and Baten (2005) show, nutrition seems to have some role in explaining the regional differentials as Northern Europe had the tallest heights accompanied by lower population density and higher protein production per capita the same case can be made for Australia and the United States in the antebellum, see e.g., Steckel, 2005a). Variations in climate and other influences such as gender and social inequality also seem to have played a role in long-term variations in height (see Köepke \& Baten, 2005).

Evidence for Europe thus suggests that height declined after the Middle Ages and reached its lowest point in the 17 th century. The recovery in the 18 th century was only short lived because the population's nutritional status diminished. Overall, it seems that the 17th century presented the lowest heights in modern times, and while the 17th century "nadir was never again reached, and a subsistence crisis was ultimately averted, in many cases not until the turn of the 20th century did European heights exceed the levels of the early 18 th century" (Komlos \& Cinnirella, 2005, p. 3).

Multiple reasons explain the modern movements in heights and the parallel changes in life expectancy. Baten (2002) shows that colder winters beginning in the late 1750 s lowered grain and protein production, leading to reductions in physical stature in southern Germany. Proximity to nutrient production, especially for milk production, had a positive effect on average height (see Baten, 2000-01). Meat consumption also contributed to significantly increase the heights in the 19th-century France while the early fertility decline in France had a beneficial influence on stature (see Weir, 1997, 1993). An alternative and more direct channel between wages and height could be established in continental Europe and Scandinavia for some periods (see Baten, 2000-01 where methodological issues are also addressed), but, as noted in the previous sub-section, after 1820 heights and real wages in England and in the United States diverged, giving rise to the "antebellum puzzle" (see Komlos, 1998 for a detailed study).

A definite analysis on the cause of the decline in height associated with industrialization is not yet available. Due to the inadequate sanitation in cities, urbanization and compositional changes in the population seem to be a first-order factor. Still, as not all groups were affected by the decline (see Komlos, 1998), other influences seem also relevant for the decline in heights. Additional factors include changes in food prices and a shift away from protein consumption, market integration and the spread of disease affiliated with the development of railroads, canals, and steamboats (i.e., Baten \& Fertig, 2005), the widening of income inequality, a large influx of unskilled workers into cities, and the allocation of nutritious foods to the market rather than to household consumption (see Komlos \& Baten, 2004 for an authoritative review on recent advances in anthropometric history). ${ }^{14}$

(e) Along with tuberculosis, some endemic diseases particularly sensitive to nutritional status and adequate nursing started to decline in the 18 th century prior to any health intervention. 
According to McKeown (1976), the decline of tuberculosis and airborne diseases in general can only be explained by gains in nutrition because no other intervention could have effectively contributed to the decline of these diseases.

The reclassification of diseases by Woods (2000, Table 8.7) corrects the big emphasis. McKeown (1976) placed on respiratory diseases, but it is nonetheless consistent with the prominent role of tuberculosis and mortality from infectious diseases. In Woods (2000), tuberculosis still represents the highest decline of a single condition with a contribution of $35 \%$ to the mortality decline during 1860 1900 , followed by scarlet fever and waterborne diseases such as typhus and diarrhea. By the middle of the 20th century, mortality from tuberculosis and other respiratory infections had substantially declined prior to any effective medical treatment.

Yet, the analysis of McKeown (1976) provides a limited view in a number of respects. For example, by the synergism between nutrition and infection, or the fact that malnutrition is not exclusively determined by diets, airborne and waterborne diseases cannot be treated as independent in an accounting exercise as McKeown (1976) did, see Preston (1975), and Preston and Van de Walle (1978). Harris (2004) revisits McKeown's thesis and provides the much-needed qualifications.

(f) Early ages determined the overall differentials in urban-rural mortality and served to illustrate the contribution of public health measures to the mortality transition of cities. ${ }^{15}$ Although cause-specific mortality statistics are not available for the initial phase of the mortality decline, the cross-sectional distribution of seasonal patterns in late 19th-century England shows that during 1870-99 infant mortality was higher in cities by a summer peak related to water and foodborne diseases and not by diseases sensitive to nutrition, which tend to have a strong seasonality in the winter (see Figures 1 and 2).

Changes in the seasonality of infant mortality are particularly useful to examine mortality change because infectious diseases follow wellestablished seasonal patterns. ${ }^{16}$ The seasonality in infant mortality shows the effects of the urbanization that followed the Industrial Revolution and how public health interventions controlled the gastrointestinal diseases responsible

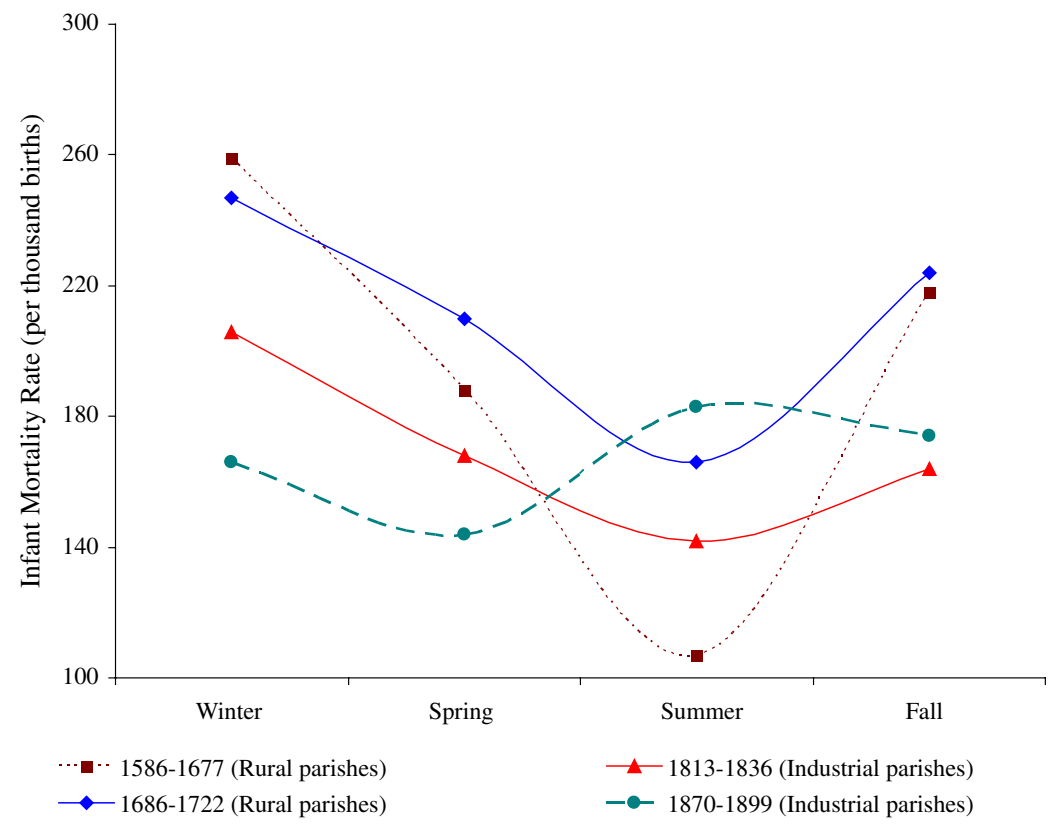

Figure 1. Quarterly IMR in selected areas. England and Wales, 1586-1899. IMR for 1586-1677 and 1686-1722 from the parishes of Selattyn and Kinneley in Jones (1980, Table 6). Industrial parishes for 1813-36 and the matching registration districts for 1870-99 are from Huck (1997, Table 2). 


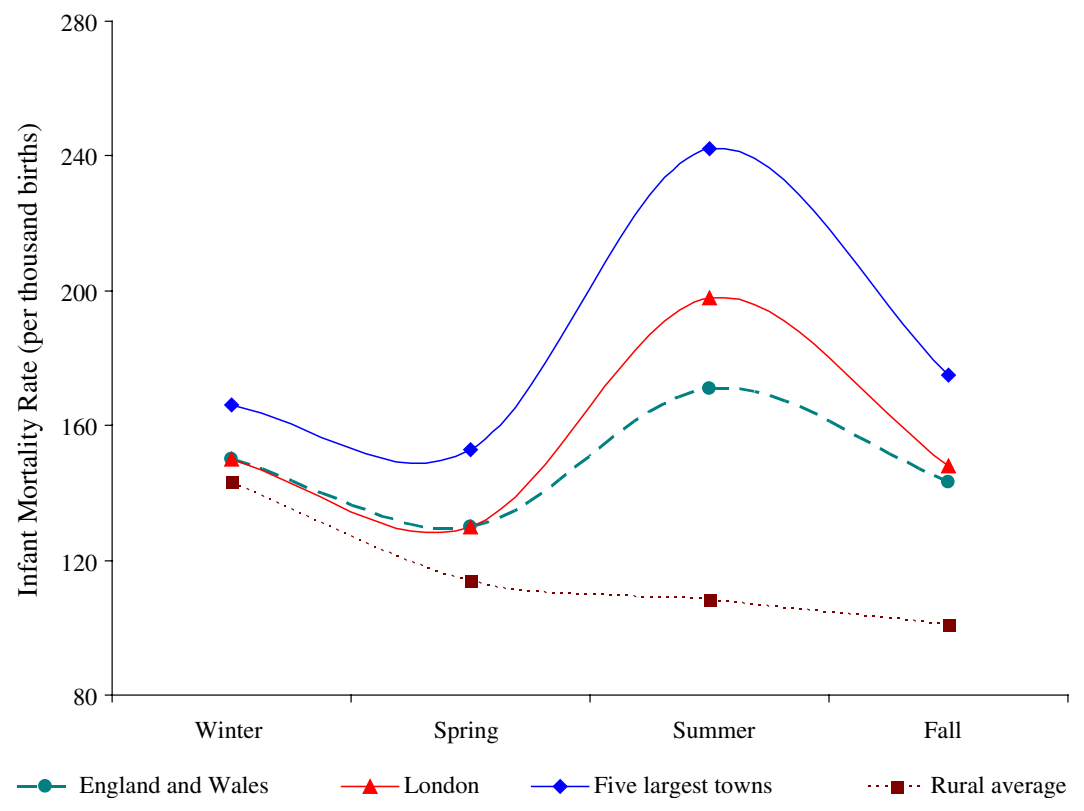

Figure 2. Quarterly IMR. England and Wales, 1870-99. Data from Huck (1997, Table 2) based on official registration data. The five largest towns are Liverpool, Birmingham, Manchester, Leeds, and Sheffield.

for the summer peak during the late 19th century. Direct evidence of cause-specific mortality rates for three industrial and three rural towns in England during 1889-91, provided by Williams and Galley (1995, Table 3), confirms the disproportionate effect of gastrointestinal conditions in urban populations.

Seasonality changes in infant mortality rates also suggest that a winter mortality decline in rural areas, potentially related to respiratory diseases, started at the end of the 18th century and continued in urban areas but was outnumbered by a sharp increase in summer mortality in urban areas (Figure 1). A strong seasonality in mortality, with summer as the least mortal season, is a well-established characteristic of pre-industrial England and Wales (Wrigley et al., 1997, Figure 6.24).

It is not uncommon in aggregate analyses of population growth to interpret the lack of any downward trend in death rates before the late 19 th century as evidence of no mortality decline when a constant mortality rate was actually just the reflection of two offsetting tendencies (see Table 2 and Figure 1). That the pressure of urbanization on mortality disappeared indicates that public sanitation had a large impact on reversing the urban penalty in the late 19th century, but it seems very unlikely that public health measures were the main factor behind the initial escape from high mortality in developed countries.

\section{THE MORTALITY OF POOR COUNTRIES}

Differences in mortality within less developed countries exist (Figure 3), but even in the countries with the lowest life expectancy, mortality at the end of the 20th century was well below that experienced by Northwestern Europe in the 18 th century. ${ }^{17}$ Also, similar to the mortality decline in rich countries, most gains in life expectancy have to be attributed to a lower mortality during early years and not to extended life spans for the old-age population. The case of Brazil and India, summarized in Table 4, shows once again the disproportionate effect of the mortality decline at early ages. The table also shows that as in the historical experience of developed countries, the age groups more vulnerable to malnutrition and environmental conditions (young children) had the highest proportional decline.

Urban-rural differentials have not influenced the epidemiological transition of poor countries 


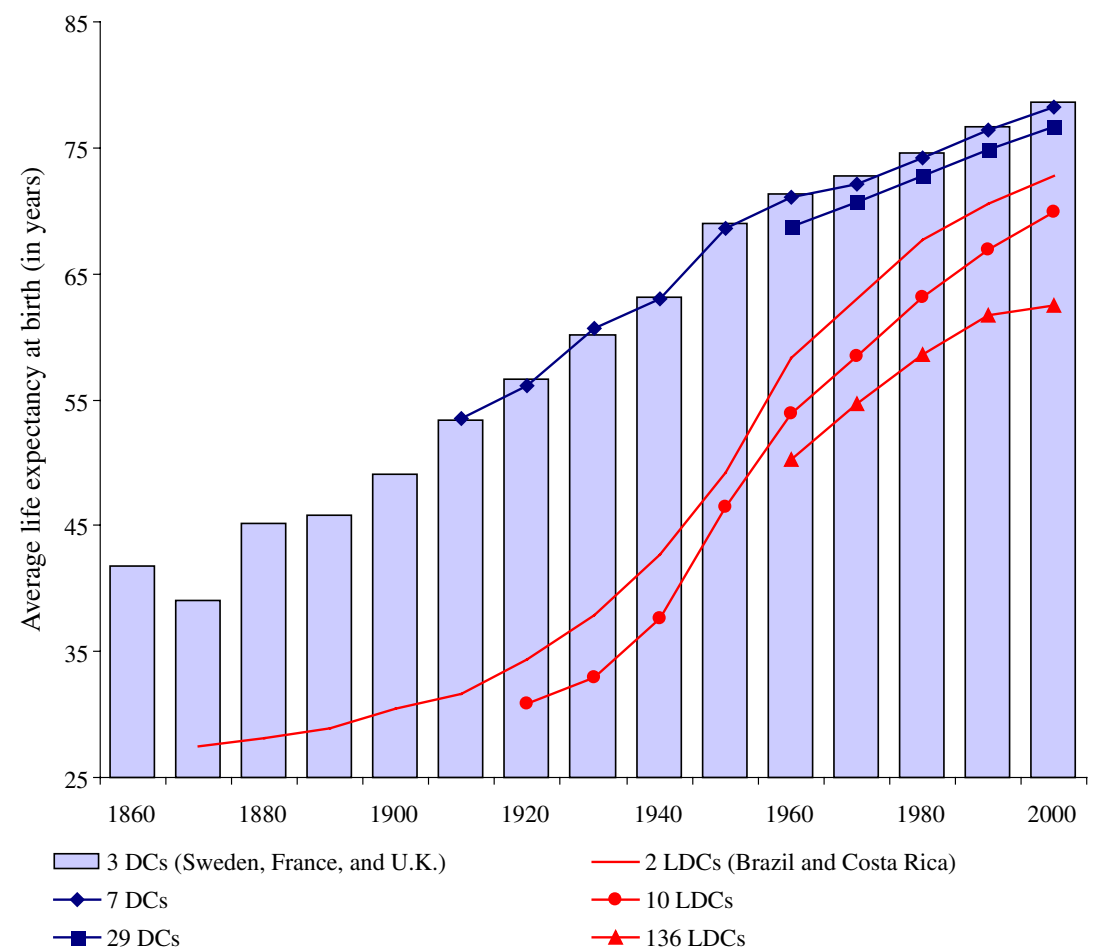

Figure 3. Average life expectancy at birth in developed and less developed countries, 1860-2000 (constant samples). Sample sizes in the figure. Data from Arriaga (1968), Keyfitz and Flieger (1986), Preston (1975), World Bank (2000), and United Nations (several years).

Table 4. Relative age-specific death rates (per thousand)

\begin{tabular}{lccccccccc}
\hline & \multicolumn{10}{c}{ Age } \\
\cline { 3 - 9 } & & 0 & $1-4$ & $5-9$ & $10-14$ & $30-34$ & $40-44$ & $60-64$ & $70-74$ \\
\hline Brazil, death rates & 257.2 & 161.4 & 87.0 & 46.0 & 91.6 & 122.6 & 263.9 & 437.0 \\
Relative death rates (1890=100) & 1890 & 100 & 100 & 100 & 100 & 100 & 100 & 100 & 100 \\
& 1920 & 88 & 82 & 83 & 89 & 86 & 82 & 88 & 93 \\
& 1960 & 41 & 26 & 23 & 24 & 27 & 27 & 47 & 62 \\
& 2000 & 14 & 6 & 2 & 5 & 13 & 17 & 34 & 44 \\
& & & & & & & & & \\
India, death rates & 287.1 & 186.8 & 67.4 & 53.7 & 113.2 & 142.4 & 330.7 & 517.7 \\
Relative death rates (1900 & 1900 & 100 & 100 & 100 & 100 & 100 & 100 & 100 & 100 \\
& & & & & & & & & \\
& 1920 & 84 & 82 & 91 & 91 & 96 & 91 & 93 & 95 \\
& 1960 & 52 & 46 & 37 & 17 & 39 & 42 & 52 & 64 \\
& 2000 & 25 & 13 & 15 & 13 & 15 & 19 & 38 & 54 \\
\hline
\end{tabular}

Brazil, 1890-2000 and India, 1900-2000.

Source: Arriaga (1968), Malaker and Roy (1990), Keyfitz and Flieger (1986), and the World Heath Organization (WHOSIS).

in a similar way as in developed countries because mortality gains in urban areas exceed by far the gains in the rural counterpart of poor countries: 
Table 5. Urban and rural IMR in less developed countries, 1980-90

\begin{tabular}{lcccc}
\hline & \multicolumn{3}{c}{ Urban areas } & Rural areas \\
\cline { 2 - 4 } & $\begin{array}{c}\text { Big cities, } \\
>1 \text { million }\end{array}$ & $\begin{array}{c}\text { Small cities, } \\
50,000-1 \text { million }\end{array}$ & $\begin{array}{c}\text { Towns, } \\
<50,000\end{array}$ & Villages \\
\hline Asia & 47.5 & 60.5 & 66.9 & 86.8 \\
Latin America and Caribbean & 65.7 & 61.5 & 74.4 & 91.9 \\
Sub-Saharan Africa & 66.7 & 86.0 & 83.5 & 99.4 \\
North Africa/Near East & 62.0 & 71.7 & 75.5 & 107.6 \\
\hline
\end{tabular}

Source: Brockerhoff and Brenna (1998).

(b') Urban areas in less developed countries, especially in big cities, have experienced an advantage over the mortality of rural areas.

Table 5 displays evidence to corroborate $\left(\mathrm{b}^{\prime}\right)$. As the table shows, infant mortality rates in rural areas always exceed the mortality rates of cities. It should come as no surprise that cities achieved lower mortality levels, especially because poor countries avoided the urban penalty in mortality as public health innovations were transferred from developed countries. As Brockerhoff and Brenna (1998, Table 4) show, the prevalence of malnutrition (represented by stunted growth), the frequency of diarrhea, and the number of inadequate sanitation facilities are higher in rural areas. Thus, the urban advantage in poor countries is likely to be the result of better sanitation and nutrition.

Finally, for (c) we should note that although famines and epidemic crises were present in many less developed countries during the 20th century, the eradication of these crises, as in developed countries, does not appear to be the fundamental reason behind low mortality. As Osmani (1998) notes, famines have longterm effects on mortality, fertility, and population growth, but their demographic impact tends to be minor because they rarely affect national mortality levels. ${ }^{18}$ HIV/AIDS in subSaharan Africa is perhaps the only mortality crisis that nowadays has a large aggregate impact on mortality change. In spite of being widespread, since HIV/AIDS mortality and morbidity mainly affect young adults (especially young women), the changes in life expectancy will not be as severe as if the epidemic affected only children. Still, the economic consequences of HIV/AIDS, as well as its future, seem hard to estimate accurately. ${ }^{19}$

Despite similarities, and the lack of harmful effects of urbanization $\left(b^{\prime}\right)$, other important differences exist for poor countries. The mortality decline in less developed countries has been fas- ter than in developed countries and less dependent on income growth. A comparison of life expectancies at birth in Figure 3 finds that while the average differences in life expectancy between poor and rich countries in 1900 and in 2000 have been reduced, the income differences are now several times larger. Figure 3 also reveals a convergence of poor countries to the life expectancy pattern set by developed countries with two features: first, in terms of the timing, most mortality gains have been achieved after 1930, and second, the fastest decline took place before 1960 . Both features suggest that the period during 1930-60 was exceptional for the mortality transition of poor countries (see also Preston, 1985). Finally, Figure 3 shows that sample selection is an important concern in the estimation of mortality gains since as the sample increases (to include African countries), the average life expectancy in poor countries declines. When the average life expectancy of less developed countries is computed with a large number of countries, it shows no marked differential in trends compared to the average life expectancy of developed countries. The reason is perhaps the changes in the former Soviet Union and sub-Saharan Africa since the 1980s (see, e.g., Bourguignon \& Morrison, 2002).

Biological measures of the standard of living, such as height, have also been considered recently as alternatives and complements to income measures in poor countries. As height is an outcome measure of health, and a proxy for welfare, Moradi and Baten (2005) use height variation to study inequality in sub-Saharan Africa, where reliable information on income inequality within and among countries is highly scarce. Moradi and Baten (2005) show that diversification in food production increases average heights (relative to the country mean) and reduces height inequality. The same effect is observed in regions with proximity to protein production and in regions with higher educational attainment. As most African 
populations still depend on agriculture for their livelihood, the significance of Moradi and Baten (2005) extends beyond the current implications for poor countries into the historical analysis. Moradi and Baten (2005) also discuss in greater detail the methodological aspects of using heights in measuring within inequality.

\section{ECONOMIC GROWTH AND MORTALITY CHANGE}

The causes of the mortality decline of poor countries have been repeatedly studied, but Preston (1980) still provides a comprehensive analysis. Preston $(1975,1980,1985)$ estimated the effect of income on mortality and showed that the relationship between both variables was subject to structural changes, or that part of the mortality gains were unrelated to income growth but were related to factors considered exogenous. The specific contribution varied according to the sample used and especially with the period of consideration. For example, according to Preston (1980), economic development as measured by per capita income accounts for about $30 \%$ of the improvement in life expectancy from the 1940s to the 1970s in less developed countries. In terms of the world mortality decline during 1930-60, Preston (1975) estimates that only a small part of the gains in mortality was related to changes in income, with exogenous changes accounting for as much as $85 \%$ of the decline. Finally, an update in Preston (1985) estimates that economic variables were the dominating factor in explaining the mortality decline during the 1965-69 to 1975-79 decade.

Alternative estimates of the effect of aggregate income on mortality based on IV are available. ${ }^{20}$ For example, Pritchett and Summers (1996) concluded that income growth is able to explain $40 \%$ of the gains in world mortality since 1960 if income is instrumented by the investment ratio and the black market premium. ${ }^{21}$

\section{(a) Data}

In order to study modern mortality change, we employ cause (and age-) specific mortality statistics from the WHOSIS. The WHOSIS Mortality Database contains registered deaths by age group, sex, year, and cause of death officially reported by WHO member states that have universal registration of deaths and a high level of certification of cause of death. ${ }^{22}$ The first year of data is 1950, but the number of countries for which data are available varies from year to year. Also, the existence and completeness of a time series of data varies by country, so most of our estimates consider unbalanced panels. Fairly complete series exist for developed countries and for Latin America. Outside of Latin America, a very few less developed countries present robust time series, and only Mauritius is included from sub-Saharan Africa.

The cause-of-death labels vary over time according to the version of the International Statistical Classification of Diseases and Related Health Problems (ICD) used; so, for comparability, we classified death rates by the different versions of the ICD according to the codes described in Appendix A. We disaggregate infectious disease mortality to study the variations in the causes of death for specific diseases as most of the gains in mortality are due to lower prevalence and fatality of infectious diseases.

A broad analysis of mortality by age groups is provided in Table 6 . The table confirms the remarkable gains in infant and child mortality rates during the last decades in developed countries, but especially in less developed countries. The table also corroborates the patterns described above, so no additional explanation of the facts seems necessary.

Cause-specific mortality rates are presented in Table 7 but only for infectious diseases in less developed countries, since they are the most important component of the secular mortality decline in poor countries. The analysis of cause-specific death rates generates a wellrecognized epidemiological pattern (Omran, 1971). Mortality from infectious diseases has declined with their decline as the main reason for the increase in life expectancy. In terms of the causes responsible for low mortality, the conditions considered in the paper cover most of the diseases that have made a significant contribution to mortality. By its relative importance in the 1960 s, mortality from airborne diseases such as tuberculosis, whooping cough, and measles had the largest contribution to the decline followed by waterborne diseases such as typhoid fever, cholera, and dysentery. With the notable exception of malaria, all diseases for which the influence of nutrition is expected to be minimal or variable did not change markedly in the sample. The reduction in mortality from malaria was con- 
Table 6. Average age-specific death rates (per thousand) in developed and less developed countries

\begin{tabular}{|c|c|c|c|c|}
\hline \multirow[t]{2}{*}{ Age group } & \multicolumn{2}{|c|}{ Developed countries } & \multicolumn{2}{|c|}{ Less developed countries } \\
\hline & $1950-69$ & $1980-99$ & $1950-69$ & $1980-99$ \\
\hline 0 & $\begin{array}{c}30.69 \\
(14.00)\end{array}$ & $\begin{array}{c}9.96 \\
(4.88)\end{array}$ & $\begin{array}{c}73.01 \\
(41.02)\end{array}$ & $\begin{array}{c}22.18 \\
(17.21)\end{array}$ \\
\hline $1-4$ & $\begin{array}{l}1.70 \\
(1.22)\end{array}$ & $\begin{array}{c}0.52 \\
(0.13)\end{array}$ & $\begin{array}{c}9.78 \\
(8.02)\end{array}$ & $\begin{array}{c}1.53 \\
(2.27)\end{array}$ \\
\hline $5-24$ & $\begin{array}{c}0.72 \\
(0.13)\end{array}$ & $\begin{array}{c}0.49 \\
(0.11)\end{array}$ & $\begin{array}{c}1.68 \\
(0.941)\end{array}$ & $\begin{array}{c}0.75 \\
(0.38)\end{array}$ \\
\hline $25-44$ & $\begin{array}{c}1.92 \\
(0.37)\end{array}$ & $\begin{array}{c}1.42 \\
(0.59)\end{array}$ & $\begin{array}{c}3.55 \\
(1.30)\end{array}$ & $\begin{array}{c}2.24 \\
(0.93)\end{array}$ \\
\hline$\geqslant 45$ & $\begin{array}{l}25.85 \\
(3.77)\end{array}$ & $\begin{array}{l}25.20 \\
(4.96)\end{array}$ & $\begin{array}{l}23.87 \\
(5.15)\end{array}$ & $\begin{array}{l}23.54 \\
(5.53)\end{array}$ \\
\hline CDR & $\begin{array}{c}9.27 \\
(2.06)\end{array}$ & $\begin{array}{c}9.15 \\
(2.46)\end{array}$ & $\begin{array}{c}9.41 \\
(2.69)\end{array}$ & $\begin{array}{c}6.79 \\
(2.53)\end{array}$ \\
\hline ASDR & $\begin{array}{c}8.72 \\
(0.97)\end{array}$ & $\begin{array}{c}6.97 \\
(1.40)\end{array}$ & $\begin{array}{l}11.34 \\
(2.95)\end{array}$ & $\begin{array}{c}8.09 \\
(1.56)\end{array}$ \\
\hline No. obs./no. countries & $474 / 30$ & $544 / 32$ & $284 / 33$ & $394 / 50$ \\
\hline
\end{tabular}

Note: The means are obtained from an unbalanced panel. Less developed countries according to the World Bank classification. CDR represents crude death rates and ASDR the age standardized death rate. Death standardization with the WHO standard population. Standard deviations between countries in parentheses. The data treat countries that belong to the former Soviet Union as less developed for the latest years, but the effects are minimal if they are considered developed countries.

sidered by Preston (1980) as the fundamental exogenous innovation in public health responsible for the rapid mortality decline in poor countries before 1970 .

Due to the contribution of tuberculosis, the mortality decline of less developed countries appears closer to the historical experience of England and Wales described in the second to last column of Table 7. The absolute contribution of each factor differs from Preston's (1980) estimate, possibly because of differences in the periods under consideration. Preston (1980) covered the 1940-70 years when major public health innovations took place (Figure 3). Still, in the mortality decline of less developed countries, the role of influenza/pneumonia/bronchitis (which in Preston, 1980 accounted for 30\% of all gains), tuberculosis $(10 \%)$, and waterand food-borne diseases $(9 \%)$ represented about $50 \%$ of the total decline. According to Preston (1980, p. 301), these diseases highlight the significance of "poor nutrition as a factor underlying high mortality rates in less developed countries." The importance of nutritional status seems quite robust since, as Preston (1980) notes, there are not preventive measures for respiratory conditions.

The importance of respiratory conditions for life expectancy changes during 1960-2000 was also documented by Becker et al. (2005) in mea- suring modern changes in the quality of life and health inequality. As Becker et al. (2005) also use WHOSIS data, their estimates do not incorporate sub-Saharan Africa, where mortality has increased during the last decades (see Figure 3). ${ }^{23}$

Specific information for different age groups is also available, but due to space limitation (and uniformity) their descriptive analysis is omitted. Instead, we consider two alternative estimation strategies to represent and measure the effect of income growth for the mortality decline. We obtained annual data for income from the Penn World Table 6.1 (see Heston, Summers, \& Aten, 2002) that provides income per capita information for 179 countries for the period 1950-2000. Real GDP per capita is measured in PPP. The investment rate employed later on is also from Heston et al. (2002).

\section{(b) Technological change in mortality}

To measure the contribution of income growth to mortality, the levels of mortality and income can be related to one another in a variety of ways. For example, the effects of income can be estimated as in the models of technological change comparing the effects of income holding all else constant (as in the index 
Table 7. Cause-specific ASDR (per million) and mortality change by nutritional influence, 1950-99

\begin{tabular}{|c|c|c|c|c|c|}
\hline & \multicolumn{2}{|c|}{$\begin{array}{c}\text { Death rate in less } \\
\text { developed } \\
\text { countries }\end{array}$} & \multicolumn{3}{|c|}{ Percent contribution } \\
\hline & $1950-69$ & $1980-99$ & $\begin{array}{l}\text { Less developed } \\
\text { countries }\end{array}$ & $\begin{array}{c}\text { England and } \\
\text { Wales } 1861-1900\end{array}$ & $\begin{array}{l}\text { Preston }(1980) \\
\text { estimate } 1900-70\end{array}$ \\
\hline \multicolumn{6}{|l|}{ A. Definite influence } \\
\hline Measles & 64.4 & 10.4 & 10.74 & -0.74 & 1 \\
\hline Dysentery & 53.8 & 2.5 & 10.18 & & 7 \\
\hline Respiratory tuberculosis & 300.1 & 62.0 & 47.30 & 35.19 & 10 \\
\hline Whooping cough & 48.3 & 4.5 & 8.71 & 2.52 & 1 \\
\hline Cholera & 13.4 & 5.3 & 1.62 & 6.86 & 1 \\
\hline \multicolumn{6}{|l|}{ B. Variable influence } \\
\hline Typhus & 7.8 & 0.4 & 1.47 & 21.29 & 1 \\
\hline Diphtheria & 8.3 & 1.2 & 1.41 & -2.84 & 1 \\
\hline Non-respiratory tuberculosis & 7.9 & 1.9 & 1.20 & -6.81 & \\
\hline Scarlet fever & 1.5 & 1.3 & 0.03 & 22.46 & \\
\hline \multicolumn{6}{|l|}{ C. Minimal influence } \\
\hline Smallpox & 3.4 & 0.7 & 0.55 & 4.27 & 2 \\
\hline Malaria & 72.4 & 10.3 & 12.34 & & $13-33$ \\
\hline Plague & 0.9 & 0.2 & 0.14 & & 1 \\
\hline Typhoid fever & 26.1 & 5.8 & 4.03 & & 1 \\
\hline Meningococcal infections & 2.8 & 2.8 & 0.01 & & \\
\hline Poliomyelitis & 3.7 & 1.4 & 0.47 & & \\
\hline Other infectious diseases & 28.8 & 29.8 & -0.19 & & \\
\hline Average no. obs./total & 278 & 388 & 100.00 & 82.19 & $39-59$ \\
\hline
\end{tabular}

Note: Death rates are taken as standardized per million rather than per thousand as in Table 6. Disease groups are described in Appendix A. The nutritional influence is taken from the Conferees (1983, Figure 3) and Lunn (1991, Table 7.2). Data for England and Wales are taken from Woods (2000, Table 8.7). The contribution of each condition was not re-scaled to obtain $100 \%$. The conditions renamed to modern diseases are phthisis to respiratory tuberculosis and diarrhoea to cholera. Scrofula is represented as non-respiratory tuberculosis. In the estimates from Preston (1980, Table 5.3), we divided diphtheria and whooping cough equally.

of technological change of Baltagi \& Griffin, 1988 ) or looking at pairwise comparisons between decades (as Preston, 1975, 1980, 1985). Since there are period-specific influences that operate on mortality in all countries, variations along a cross-section are more commonly employed.

First, assume that the technology that determines mortality due to cause of death $j$ is a function of time, $A_{j}(t)$. The specification with an index of technical change $A_{j}(t)$ can be understood as follows:

$d_{i j t}=\boldsymbol{\alpha}_{j}+\boldsymbol{\beta}_{j} \ln \left(y_{i t}\right)+\boldsymbol{\phi}_{j} A_{j}(t)+\boldsymbol{\mu}_{j} X_{j}+\zeta_{i j t}$,

where $i$ is the index for countries, $t$ for time, and $j$ represents the cause of death. $\zeta_{i j t}$ could include a country effect to capture time-invariant characteristics and also possibly correlated effects across time for each country. $X_{j}$ represents additional controls in the regression. As in
Baltagi and Griffin (1988), we consider $A(t)=t$ under the assumption of constant technological improvements in mortality (increasing or decreasing changes at a constant rate). ${ }^{24}$ Hence, the estimates of $\boldsymbol{\beta}_{j}$ represent the effect of income on mortality once technology changes at a constant exogenous rate.

\section{(c) Decomposing mortality change}

The following discussion shows one way of decomposing the difference in average death rates over time when cross-sectional estimates for periods $s$ and $t$ are used. A decomposition of the mortality gains into sources is explained next ( $X_{j}$ is omitted without loss of generality). Since a linear regression passes through the average values of the sample in (1), we can write the average mortality decline in condition $j$, between $s$ and $t$ as 


$$
\begin{aligned}
\mathbb{E}\left(d_{i j s}\right)-\mathbb{E}\left(d_{i j t}\right)= & {\left[\mathbb{E}\left(\boldsymbol{\alpha}_{j s}\right)+\mathbb{E}\left(\boldsymbol{\beta}_{j s} \ln \left(y_{i s}\right)\right)\right] } \\
& -\left[\mathbb{E}\left(\boldsymbol{\alpha}_{j t}\right)+\mathbb{E}\left(\boldsymbol{\beta}_{j t} \ln \left(y_{i t}\right)\right)\right] \\
= & \left\{\mathbb{E}\left(\ln \left(y_{i s}\right)\right)-\mathbb{E}\left(\ln \left(y_{i t}\right)\right)\right\} \overline{\boldsymbol{\beta}}_{j} \\
& +\overline{\boldsymbol{\alpha}}_{j}+\left\{\boldsymbol{\beta}_{j s}-\boldsymbol{\beta}_{j t}\right\} \ln \left(\bar{y}_{i}\right),
\end{aligned}
$$

where $\mathbb{E}$ represents the sample average taken over the cross-section of countries and $\bar{\alpha}_{j}$ is given by $\overline{\boldsymbol{\alpha}}_{j}=\mathbb{E}\left(\boldsymbol{\alpha}_{j s}-\boldsymbol{\alpha}_{j t}\right)$. Also, $\overline{\boldsymbol{\beta}}_{j}=\boldsymbol{\gamma} \boldsymbol{\beta}_{j t}+$ $(1-\boldsymbol{\gamma}) \boldsymbol{\beta}_{j s}$, and $\ln \left(\bar{y}_{i}\right)=\boldsymbol{\gamma} \mathbb{E}\left(\ln \left(y_{i s}\right)\right)+(1-\boldsymbol{\gamma}) \mathbb{E}$ $\left(\ln \left(y_{i t}\right)\right)$, or weighted averages of the coefficients and the explanatory variables. Because the estimated parameters are different, the choice of the weights $\gamma$ will affect the contribution of each factor. As suggested by Oaxaca and Ransom (1994), we take $\gamma$ as the ratio between the second moments of the independent variables, that is, of $\operatorname{Var}\left(\ln \left(y_{i t}\right)\right)$ and $\operatorname{Var}\left(\ln \left(y_{i s}\right)\right)+\operatorname{Var}\left(\ln \left(y_{i t}\right)\right)$ with variations defined over the cross-section of countries.

$\left\{\mathbb{E}\left(\ln \left(y_{i s}\right)\right)-\mathbb{E}\left(\ln \left(y_{i t}\right)\right)\right\} \overline{\boldsymbol{\beta}}_{j}$ represents the portion of the mortality decline due to cause $j$ attributable to changes in income per capita evaluated using the (weighted) average parameter estimates. If income is unimportant, this expression will be near zero.

\section{ESTIMATION RESULTS AND DECOMPOSITIONS}

At least three problems arise in the empirical analysis of mortality and income: unobserved country-specific effects, endogeneity of regressors, and simultaneity. The presence of country effects produces results that may be affected by an omitted variables bias. The bias can be attenuated by country-specific effects that control for missing or unobserved variables. Estimates might also be biased by the possibility that lagged mortality affects Eqn. (1). To minimize the extent of the biases, we considered dynamic panel models (i.e., Arellano \& Bond, 1991; Blundell \& Bond, 1998) as well as standard OLS estimators for comparison. For endogeneity, we rely on instruments from the residual structure in Arellano-Bond panel estimators and consider additional instruments often employed in the economic growth literature for robustness checks.

Table 8 presents OLS estimates (with time trends) with and without country effects. We pooled developed and less developed countries in the estimation and considered only cases with reported deaths to avoid the imputation of zero mortality rates (as this would lead to non-normality in residuals among other statistical problems).

The income gradients confirm the importance of economic development for low mortality and the epidemiological transition. However, the estimates are likely to be biased because, in the absence of controls for country-specific effects, OLS induces an upward bias by the positive correlation between income and the fixed effects, while estimates with the fixed effects will induce a downward bias by the correlation of deviations of income from its mean and the error term. As Table 8 shows, the results tend to confirm the previous biases because in almost all the fixed-effects estimators, income per capita fails to be statistically significant while almost all random-effects estimates of income are negative and highly significant.

As mortality rates exhibit high persistence within countries, we include a lagged value of death rates $d_{i j t-1}$ in Eqn. (1). This term is basically a quasi-difference for Arellano-Bond (see Blundell \& Bond, 1998 for analysis of the system GMM estimator). The inclusion of $d_{i j t-1}$, however, leads to a correlation with $\varepsilon_{i j t}$. To deal with this problem, dynamic panel estimators obtain identification from the structure of the residuals using lagged levels and first differences of income as instruments. ${ }^{25}$ Our regressions use instruments based on the second to fifth lags of the endogenous variables and employ robust standard errors and test statistics that correct for the finite sample (for further discussions see Roodman, 2003). Longer lags as instruments will probably result in biased estimates as they will have low correlation with income and can only introduce small sample bias in the estimates.

The results of estimates using age- and causespecific mortality rates are reported in Table 9. Negative and significant estimates of income on mortality can be found in the youngest age groups and for diseases for which the influence of nutrition is important. Strong negative effects exist for infant and child mortality rates. The decomposition by age groups also reveals that in the aggregate mortality rates, ASDR, income is dominated by exogenous influences in terms of its predictive power for mortality. Still, income has a negative and statistically significant influence on the youngest groups of the population. Those groups, as mentioned before, are responsible for most of the decline in mortality in the world. 
Table 8. OLS estimators of income per capita in world mortality, 1950-2003

\begin{tabular}{|c|c|c|c|c|c|c|c|c|}
\hline & \multicolumn{4}{|c|}{ Fixed effects } & \multicolumn{4}{|c|}{ Random effects } \\
\hline & $\boldsymbol{\beta}_{j}$ & S.e. & $\phi_{j}$ & S.e. & $\boldsymbol{\beta}_{j}$ & S.e. & $\phi_{j}$ & S.e. \\
\hline \multicolumn{9}{|l|}{ A. Age group } \\
\hline 0 & -1.44 & 1.82 & $-1.04^{*}$ & 0.06 & $-17.95^{*}$ & 1.53 & $-0.64^{*}$ & 0.04 \\
\hline $1-4$ & 0.63 & 0.32 & $-0.12^{*}$ & 0.01 & $-1.97^{*}$ & 0.28 & $-0.05^{*}$ & 0.00 \\
\hline $5-24$ & -0.04 & 0.04 & $-0.01^{*}$ & 0.00 & $-0.32^{*}$ & 0.03 & $-0.00^{*}$ & 0.00 \\
\hline $25-44$ & $-0.24^{*}$ & 0.08 & $-0.02^{*}$ & 0.00 & $-0.65^{*}$ & 0.05 & $-0.01^{*}$ & 0.00 \\
\hline$\geqslant 45$ & 0.50 & 0.47 & $-0.06^{*}$ & 0.01 & 0.64 & 0.42 & $-0.05^{*}$ & 0.01 \\
\hline ASDR & -0.31 & 0.23 & $-0.07^{*}$ & 0.00 & $-1.98^{*}$ & 0.22 & $-0.03^{*}$ & 0.00 \\
\hline \multicolumn{9}{|l|}{ B. Definite influence } \\
\hline Measles & 7.59 & 4.07 & $-0.95^{*}$ & 0.16 & -16.78 & 10.94 & -0.26 & 0.33 \\
\hline Dysentery & 5.98 & 4.14 & $-1.09^{*}$ & 0.13 & $-7.93^{*}$ & 3.16 & $-0.70^{*}$ & 0.08 \\
\hline Respiratory tuberculosis & $-191.1^{*}$ & 24.8 & -1.33 & 0.71 & $-129.5^{*}$ & 12.28 & $-3.15^{*}$ & 0.40 \\
\hline Whooping cough & 1.09 & 3.19 & $-0.79^{*}$ & 0.10 & $-8.74^{*}$ & 2.74 & $-0.52^{*}$ & 0.07 \\
\hline Cholera & -6.44 & 7.62 & 0.27 & 0.33 & $-5.14^{*}$ & 2.62 & -0.02 & 0.15 \\
\hline \multicolumn{9}{|l|}{ C. Variable influence } \\
\hline Typhus & $3.64^{*}$ & 1.09 & $-0.20^{*}$ & 0.04 & -0.31 & 0.29 & $-0.08^{*}$ & 0.02 \\
\hline Diphtheria & $-3.19^{*}$ & 0.67 & $-0.18^{*}$ & 0.02 & $-3.58^{*}$ & 0.35 & $-0.16^{*}$ & 0.01 \\
\hline Non-respiratory tuberculosis & $-4.86^{*}$ & 1.07 & -0.04 & 0.02 & $-3.71^{*}$ & 0.79 & $-0.07^{*}$ & 0.02 \\
\hline Scarlet fever & -0.05 & 0.23 & -0.00 & 0.00 & -0.05 & 0.11 & -0.00 & 0.00 \\
\hline \multicolumn{9}{|l|}{ D. Minimal influence } \\
\hline Smallpox & $20.05^{*}$ & 8.37 & $-0.70^{*}$ & 0.28 & $-1.53^{*}$ & 0.49 & -0.03 & 0.03 \\
\hline Malaria & 0.09 & 7.57 & $-0.73^{*}$ & 0.22 & -15.23 & 14.46 & -0.31 & 0.41 \\
\hline Plague & -0.99 & 1.28 & 0.01 & 0.02 & -0.16 & 0.14 & -0.00 & 0.00 \\
\hline Typhoid fever & 1.54 & 1.57 & $-0.47^{*}$ & 0.06 & $-4.87^{*}$ & 1.19 & $-0.27^{*}$ & 0.03 \\
\hline Meningococcal infections & $0.94^{*}$ & 0.32 & $-0.07^{*}$ & 0.00 & 0.42 & 0.35 & $-0.05^{*}$ & 0.01 \\
\hline Poliomyelitis & $-4.17^{*}$ & 1.12 & $-0.11^{*}$ & 0.02 & $-1.27^{*}$ & 0.62 & $-0.19^{*}$ & 0.03 \\
\hline Other infectious diseases & -3.04 & 1.89 & $0.16^{*}$ & 0.06 & $-15.62^{*}$ & 2.45 & $0.46^{*}$ & 0.08 \\
\hline
\end{tabular}

Note: Estimates obtained by OLS regressions with $A(t)=t$ in Eqn. (1). Definitions as in Table 6 . The number of observations in part A is 1,887 and for the other parts is over 1,000 in all cases except in the case of Cholera (148), Typhus (592), Smallpox (68), Plague (59), and Polio (996). This is because in all estimations the sample includes countries with reported death rates. No imputation of zero mortality was done. S.e. denotes robust standard errors of the estimator.

* Significant at $p<0.05$.

Measles, respiratory tuberculosis, whooping cough, dysentery, and diphtheria display a negative relation with income as the Conferees (1983, Figure 3) and Lunn (1991, Table 7.2) would suggest. Diseases on which nutritional status has a minimal effect exhibit zero correlation with income per capita. That is the case for scarlet fever, smallpox, plague, meningococcal infections, malaria, and poliomyelitis. Typhoid fever is the only infectious disease in which the epidemiological literature finds minimal influence of nutrition but still responds negatively to income. Table 9 also shows that the estimates fail to reject the null hypothesis for Hansen's $J$ overidentifying restrictions test in all cases. First- and second-order autocorrelation tests show that first-order correlation is not in general present, although some $p$-values for the test on $\mathrm{AR}(1)$ are below 0.05 . As identification builds on no second-order correlation, the problems due to time dependence are not a major concern.

Instead of pooling all countries, we consider only the sample of poor countries. The estimates for the sample of less developed countries in Table 10 are smaller and often fail to be statistically significant. The reason is a smaller cross-sectional component in the estimation and a smaller sample size leaving less to be explained. It is clear that developed and less developed countries differ by aspects other than income per capita. However, it is not clear that the factors responsible for the differences in mortality grant a separate analysis of both groups.

Estimates with additional controls and IV are presented in Table 11. For robustness, 
Table 9. Dynamic panel (system GMM) estimators

\begin{tabular}{|c|c|c|c|c|c|c|c|c|c|}
\hline & \multicolumn{6}{|c|}{ Estimates } & \multicolumn{3}{|c|}{ Tests ( $p$-values) } \\
\hline & $\boldsymbol{\beta}_{j}$ & S.e. & $\phi_{j}$ & S.e. & $\rho_{j}$ & S.e. & $J$ & $\mathrm{AR}(1)$ & $\mathrm{AR}(2)$ \\
\hline \multicolumn{10}{|l|}{ A. Age group } \\
\hline 0 & $-27.82^{*}$ & 7.15 & -0.22 & 0.15 & $0.10^{*}$ & 0.14 & 1.00 & 0.32 & 0.32 \\
\hline $1-4$ & $-1.90^{*}$ & 0.75 & 0.00 & 0.01 & $0.66^{*}$ & 0.11 & 1.00 & 0.28 & 0.31 \\
\hline $5-24$ & $-0.22^{*}$ & 0.05 & -0.00 & 0.00 & $0.55^{*}$ & 0.06 & 1.00 & 0.30 & 0.31 \\
\hline $25-44$ & $-0.49^{*}$ & 0.07 & 0.00 & 0.00 & $0.53^{*}$ & 0.04 & 1.00 & 0.30 & 0.31 \\
\hline$\geqslant 45$ & 0.23 & 0.51 & -0.02 & 0.02 & $0.54^{*}$ & 0.01 & 1.00 & 0.30 & 0.31 \\
\hline ASDR & -0.67 & 0.49 & $-0.02^{*}$ & 0.01 & $0.49^{*}$ & 0.00 & 1.00 & 0.31 & 0.32 \\
\hline \multicolumn{10}{|l|}{ B. Definite influence } \\
\hline Measles & $-43.13^{*}$ & 15.40 & 0.47 & 0.40 & 0.20 & 0.20 & 1.00 & 0.29 & 0.47 \\
\hline Dysentery & $-4.97^{*}$ & 2.27 & $-0.12^{*}$ & 0.04 & $0.74^{*}$ & 0.05 & 1.00 & $0.05^{*}$ & 0.29 \\
\hline Respiratory tuberculosis & $-156.11^{*}$ & 63.86 & 0.63 & 1.11 & $0.46^{*}$ & 0.12 & 1.00 & 0.31 & 0.31 \\
\hline Whooping cough & $-16.54^{* *}$ & 9.11 & 0.03 & 0.10 & $0.54^{*}$ & 0.21 & 1.00 & 0.32 & 0.33 \\
\hline Cholera & 0.28 & 0.56 & -0.08 & 0.08 & $0.54^{*}$ & 0.08 & 1.00 & 0.31 & 0.32 \\
\hline \multicolumn{10}{|l|}{ C. Variable influence } \\
\hline Typhus & 0.26 & 1.12 & -0.02 & 0.03 & $0.84^{*}$ & 0.03 & 1.00 & 0.23 & 0.27 \\
\hline Diphtheria & $-0.94^{*}$ & 0.40 & -0.01 & 0.01 & $0.80^{*}$ & 0.04 & 1.00 & $0.00^{*}$ & 0.54 \\
\hline Non-respiratory tuberculosis & -0.94 & 0.63 & $-0.06^{*}$ & 0.02 & 0.34 & $0.12^{*}$ & 1.00 & 0.12 & 0.31 \\
\hline Scarlet fever & -0.31 & 0.41 & 0.00 & 0.01 & $0.29^{*}$ & 0.035 & 1.00 & 0.16 & 0.32 \\
\hline \multicolumn{10}{|l|}{ D. Minimal influence } \\
\hline Smallpox & 0.47 & 150 & -1.52 & 0.99 & -0.63 & 0.76 & 1.00 & 0.37 & 0.86 \\
\hline Malaria & -2.67 & 2.13 & 0.08 & 0.05 & $0.78^{*}$ & 0.03 & 1.00 & $0.04^{*}$ & 0.48 \\
\hline Plague & -0.71 & 0.55 & -0.00 & 0.01 & 0.60 & 0.69 & 1.00 & 0.30 & 0.38 \\
\hline Typhoid fever & $-1.76^{*}$ & 0.72 & 0.01 & 0.02 & $0.80^{*}$ & 0.04 & 1.00 & $0.00^{*}$ & 0.53 \\
\hline Meningococcal infections & -0.10 & 0.66 & -0.00 & 0.01 & $0.62^{*}$ & 0.08 & 1.00 & 0.14 & 0.14 \\
\hline Poliomyelitis & -0.27 & 0.62 & -0.03 & 0.02 & $0.70^{*}$ & 0.03 & 1.00 & $0.01^{*}$ & $0.06^{* *}$ \\
\hline Other infectious diseases & $-11.18^{* *}$ & 5.96 & $0.27^{* *}$ & 0.16 & $0.60^{*}$ & 0.20 & 1.00 & 0.30 & 0.29 \\
\hline
\end{tabular}

World mortality, 1950-2003.

Note: Dynamic panel estimates obtained by regressions with $A(t)=t$ in Eqn. (1) and lagged values of death rates. $\boldsymbol{\rho}_{j}$ represents the coefficient on the first lag of death rates. S.e. denotes robust standard errors and test statistics based on Windmeijer finite sample correction (see Roodman, 2003). Instruments include second to fifth lags. $J$ denotes Hansen's test of over identifying restrictions. Additional definitions as in Table 6. The sample size in part A is 1,887. Sample sizes are above 1,000 but for Cholera (83), Typhus (408), Diphtheria (837), Scarlet fever (893), Smallpox (35), Malaria (822), Plague (27), Typhoid fever (982), and Poliomyelitis (795). No imputation of zero mortality was done. ${ }^{*}$ and ${ }^{* *}$ indicate significant values at $p<0.05$ and $p<0.10$.

and to infer additional patterns of mortality, we include the urbanization rate as a determinant of age-specific death rates (information for cause specific is not reported). We consider urbanization also as an endogenous variable and instrumented as before through the structure of residuals. We use urbanization rates as reported from the World Development Indicators World Bank (2000) that give information since 1950 on an annual basis.

As changes in urbanization take place due to economic development, it is possible that the effect of income on mortality is simply the reflection of the benefits of urbanization on mortality. Once urbanization is included as control, the measured effect for income will represent the influence of income through channels other than urbanization.

Urbanization has a negative sign in all the regressions reported in Table 11 , but is statistically different from zero only in the case of infant mortality. For infant mortality, urbanization weakens the effect of income as both are positively correlated, and higher rates of urbanization are associated with lower death rates (see Table 5). Still, the sign of the coefficient on income is negative, so not all the effects of economic development can be attributed to the amenities of cities. 
Table 10. Dynamic panel (system GMM) estimators

\begin{tabular}{|c|c|c|c|c|c|c|c|c|c|}
\hline & \multicolumn{6}{|c|}{ Estimates } & \multicolumn{3}{|c|}{ Tests ( $p$-values) } \\
\hline & $\boldsymbol{\beta}_{j}$ & S.e. & $\phi_{j}$ & S.e. & $\rho_{j}$ & S.e. & $J$ & $\operatorname{AR}(1)$ & $\operatorname{AR}(2)$ \\
\hline \multicolumn{10}{|l|}{ A. Age group } \\
\hline 0 & $-11.15^{* *}$ & 5.91 & -0.22 & 0.29 & $0.71^{*}$ & 0.21 & 1.00 & 0.31 & 0.33 \\
\hline $1-4$ & -2.29 & 1.77 & -0.05 & 0.04 & $0.54^{*}$ & 0.22 & 1.00 & 0.31 & 0.31 \\
\hline $5-24$ & -0.36 & 0.23 & $-0.01^{*}$ & 0.00 & 0.29 & 0.21 & 1.00 & 0.37 & 0.31 \\
\hline $25-44$ & -0.28 & 0.25 & $-0.02^{*}$ & 0.01 & $0.32^{*}$ & 0.13 & 1.00 & 0.34 & 0.31 \\
\hline$\geqslant 45$ & 0.66 & 3.03 & -0.03 & 0.08 & 0.23 & 0.04 & 1.00 & 0.31 & 0.31 \\
\hline ASDR & -1.21 & 1.03 & $-0.05^{* *}$ & 0.02 & $0.19^{*}$ & 0.03 & 1.00 & 0.32 & 0.31 \\
\hline \multicolumn{10}{|l|}{ B. Definite influence } \\
\hline Measles & -15.37 & 16.53 & -0.66 & 0.55 & $0.73^{*}$ & 0.08 & 1.00 & $0.01^{*}$ & 0.30 \\
\hline Dysentery & -0.05 & 3.43 & $-0.28^{* *}$ & 0.12 & $0.77^{*}$ & 0.04 & 1.00 & $0.07^{*}$ & 0.77 \\
\hline Respiratory tuberculosis & -57.85 & 42.59 & -1.21 & 1.72 & 0.66 & 0.20 & 1.00 & 0.35 & 0.31 \\
\hline Whooping cough & -3.65 & 3.54 & -0.08 & 0.12 & $0.81^{*}$ & 0.06 & 1.00 & 0.16 & 0.15 \\
\hline Cholera & 2.55 & 6.40 & -0.12 & 0.24 & 0.20 & 0.27 & 1.00 & 0.51 & 0.31 \\
\hline \multicolumn{10}{|l|}{ C. Variable influence } \\
\hline Typhus & -5.92 & 6.93 & -0.07 & 0.12 & 0.49 & 0.30 & 1.00 & 0.34 & 0.36 \\
\hline Diphtheria & -3.54 & 4.93 & -0.00 & 0.15 & $0.79^{*}$ & 0.05 & 1.00 & 0.01 & 0.27 \\
\hline Non-respiratory tuberculosis & -0.46 & 2.56 & $-0.11^{* *}$ & 0.06 & $0.24^{*}$ & 0.07 & 1.00 & 0.15 & 0.26 \\
\hline Scarlet fever & 2.71 & 1.96 & -0.03 & 0.03 & $0.27^{*}$ & 0.07 & 1.00 & 0.19 & 0.33 \\
\hline \multicolumn{10}{|l|}{ D. Minimal influence } \\
\hline Smallpox & -41.25 & 81.52 & -3.43 & 2.17 & -0.10 & 0.89 & 1.00 & 0.31 & 0.39 \\
\hline Malaria & -2.65 & 6.74 & 0.08 & 0.15 & $0.78^{*}$ & 0.04 & 1.00 & $0.04^{*}$ & 0.47 \\
\hline Plague & 0.19 & 0.12 & -0.06 & 0.06 & 0.56 & 0.70 & 1.00 & 0.30 & 0.41 \\
\hline Typhoid fever & -1.38 & 2.03 & -0.05 & 0.07 & $0.81^{*}$ & 0.04 & 1.00 & $0.02^{*}$ & 0.40 \\
\hline Meningococcal infections & 0.15 & 2.55 & 0.00 & 0.70 & 0.35 & 0.60 & 1.00 & 0.41 & 0.76 \\
\hline Poliomyelitis & $-3.22^{* *}$ & 1.89 & -0.07 & 0.05 & -0.07 & 0.23 & 1.00 & 0.18 & 0.53 \\
\hline Other infectious diseases & -8.52 & 8.38 & 0.09 & 0.27 & $0.60^{*}$ & 0.20 & 1.00 & 0.30 & 0.29 \\
\hline
\end{tabular}

Less developed countries, 1950-2003.

Note: Definitions as in Table 9. The sample size in part A is 1,887. Sample sizes are above 500 observations except for Measles (481), Whooping cough (498), Cholera (62), Typhus (156), Diphtheria (442), Scarlet fever (273), Smallpox (29), Malaria (359), Plague (11), Typhoid fever (471), Meningococcal infections (498), and Poliomyelitis (383). No imputation of zero mortality was done. ${ }^{*}$ and ${ }^{* *}$ indicate significant values at $p<0.05$ and $p<0.10$.

Table 11. Dynamic panel (system GMM) estimators in world mortality, 1950-2003

\begin{tabular}{|c|c|c|c|c|c|c|c|c|c|c|c|}
\hline & \multicolumn{8}{|c|}{ Estimates } & \multicolumn{3}{|c|}{ Tests ( $p$-values) } \\
\hline & $\boldsymbol{\beta}_{j}$ & S.e. & $\phi_{j}$ & S.e. & $\mu_{j}$ & S.e. & $\rho_{j}$ & S.e. & $J$ & $\mathrm{AR}(1)$ & $\operatorname{AR}(2)$ \\
\hline \multicolumn{12}{|c|}{ Age group } \\
\hline 0 & $-19.56^{*}$ & 5.24 & $-0.42^{*}$ & 0.14 & $-0.23^{* *}$ & 0.13 & 0.06 & 0.09 & 1.00 & 0.32 & 0.32 \\
\hline $1-4$ & $-1.64^{*}$ & 0.69 & 0.00 & 0.01 & -0.02 & 0.02 & $0.61^{*}$ & 0.09 & 1.00 & 0.29 & 0.32 \\
\hline $5-24$ & $-0.17^{*}$ & 0.05 & -0.00 & 0.00 & -0.00 & 0.00 & $0.54^{*}$ & 0.06 & 1.00 & 0.30 & 0.31 \\
\hline $25-44$ & $-0.35^{*}$ & 0.15 & -0.00 & 0.00 & -0.00 & 0.00 & $0.51^{*}$ & 0.03 & 1.00 & 0.30 & 0.31 \\
\hline$\geqslant 45$ & 0.98 & 0.88 & -0.01 & 0.02 & -0.07 & 0.08 & $0.53^{*}$ & 0.01 & 1.00 & 0.30 & 0.31 \\
\hline ASDR & -0.26 & 0.54 & $-0.03^{*}$ & 0.01 & -0.01 & 0.01 & $0.49^{*}$ & 0.00 & 1.00 & 0.31 & 0.31 \\
\hline
\end{tabular}

Note: Definitions as in Table 9. $\boldsymbol{\mu}_{j}$ represents the coefficient on urbanization rates. ${ }^{*}$ and $^{* *}$ indicate significant values at $p<0.05$ and $p<0.10$.

Investment rates and the black market premium to foreign exchange are standard instru- ments in empirical analysis of economic development (see, e.g., Easterly, 1999; Pritchett 
\& Summers, 1996). As we consider annual changes in mortality, we rely on the investment rate from the Penn World Table (Heston et al., 2002) as an instrument. It is natural for

Table 12. IV estimators of income per capita in world mortality, 1950-2003

\begin{tabular}{|c|c|c|c|c|c|c|c|c|c|}
\hline & \multicolumn{6}{|c|}{ Estimates } & \multicolumn{3}{|c|}{ Tests ( $p$-values) } \\
\hline & $\boldsymbol{\beta}_{j}$ & S.e. & $\phi_{j}$ & S.e. & $\rho_{j}$ & S.e. & $J$ & $\operatorname{AR}(1)$ & $\operatorname{AR}(2)$ \\
\hline \multicolumn{10}{|c|}{ Age group } \\
\hline 0 & $-28.41^{*}$ & 6.11 & -0.21 & 0.13 & 0.10 & 0.14 & 1.00 & 0.32 & 0.32 \\
\hline $1-4$ & $-1.62^{*}$ & 0.55 & 0.00 & 0.00 & $0.66^{*}$ & 0.11 & 1.00 & 0.28 & 0.31 \\
\hline $5-24$ & $-0.22^{*}$ & 0.03 & -0.00 & 0.00 & $0.54^{*}$ & 0.06 & 1.00 & 0.30 & 0.31 \\
\hline $25-44$ & $-0.50^{*}$ & 0.08 & 0.00 & 0.00 & $0.52^{*}$ & 0.04 & 1.00 & 0.30 & 0.31 \\
\hline$\geqslant 45$ & -0.38 & 0.49 & -0.00 & 0.01 & $0.54^{*}$ & 0.01 & 1.00 & 0.30 & 0.31 \\
\hline ASDR & -0.64 & 0.57 & $-0.02^{*}$ & 0.01 & $0.49^{*}$ & 0.00 & 1.00 & 0.31 & 0.31 \\
\hline
\end{tabular}

Note: Definitions as in Table 9. Regressions using the investment rate as instrument for income.

* Significant values at $p<0.05$.

Table 13. Percent contribution of income growth to low mortality, 1950-99

\begin{tabular}{|c|c|c|c|}
\hline & \multicolumn{3}{|c|}{ Estimates obtained from } \\
\hline & $\begin{array}{c}\text { Repeated cross-sections } \\
(1960,1990)\end{array}$ & $\begin{array}{c}\text { World sample } \\
\text { (Table 9) }\end{array}$ & $\begin{array}{c}\text { Less developed countries } \\
\text { sample (Table } 10)\end{array}$ \\
\hline \multicolumn{4}{|l|}{ A. Age group } \\
\hline 0 & 34.2 & 42.9 & 17.2 \\
\hline $1-4$ & 56.5 & 23.5 & 28.3 \\
\hline $5-24$ & 57.1 & 23.4 & 38.2 \\
\hline $25-44$ & 58.4 & 31.8 & 18.2 \\
\hline$\geqslant 45$ & $<-100$ & -36.3 & $<-100$ \\
\hline ASDR & 36.3 & 15.5 & 28.0 \\
\hline \multicolumn{4}{|l|}{ B. Definite influence } \\
\hline Measles & 72.3 & 91.5 & 32.6 \\
\hline Dysentery & 29.1 & 8.6 & 0.1 \\
\hline Respiratory tuberculosis & 26.8 & 38.0 & 14.1 \\
\hline Whooping cough & 36.4 & 31.6 & 7.0 \\
\hline Cholera & $<-100$ & 44.7 & $>200$ \\
\hline \multicolumn{4}{|l|}{ C. Variable influence } \\
\hline Typhus & 24.5 & -6.2 & 140.1 \\
\hline Diphtheria & 28.7 & 10.4 & 39.2 \\
\hline Non-respiratory tuberculosis & 21.5 & 8.2 & 4.0 \\
\hline Scarlet fever & $<-100$ & $>200$ & $<-100$ \\
\hline \multicolumn{4}{|l|}{ D. Minimal influence } \\
\hline Smallpox & 52.5 & -26.7 & $>200$ \\
\hline Malaria & 160.3 & 10.2 & 10.1 \\
\hline Plague & 59.7 & $>200$ & -60.7 \\
\hline Typhoid fever & 60.0 & 8.6 & 6.7 \\
\hline Meningococcal infections & 52.1 & 15.3 & -22.9 \\
\hline Poliomyelitis & -1.7 & 3.0 & 36.3 \\
\hline Other infectious diseases & $<-100$ & -68.7 & -52.4 \\
\hline
\end{tabular}

Note: Repeated cross-sections estimated for the average centered in 1960 and 1990 and using Eqn. (2). The value of $\gamma$ employed is 0.53 as world income inequality has remained relatively stable during the last 50 years. Average annual per capita income growth of $1.5 \%$. Additional estimates obtained with the full sample estimates of $\boldsymbol{\beta}_{j}$ reported in each table. 
investment rates to be correlated with income, and there is no straightforward reason for why investment should be included in Eqn. (1) having a direct effect in mortality, so the use of investment as an instrument seems justified. As Table 12 shows, the IV estimates in general confirm the negative effect of income in mortality and give coefficients that are only marginally different from before.

We next apply the decomposition described in (2). First, we estimate the cross-sectional regressions as Eqn. (2) requires, compute the weighted-average value of the coefficient $\overline{\boldsymbol{\beta}}_{j}$, and apply it to the difference in income between the two decades centered around 1960 and around 1990. This generates a predicted gain in mortality related to the contribution of income growth. ${ }^{26} \mathrm{We}$ also produce the decomposition using the estimates of $\boldsymbol{\beta}_{j}$ from the pooled regressions listed above. Although there are multiple estimates, they differ only slightly. For the decomposition described in Table 13, we consider the dynamic panel estimates from the world sample and the restricted sample of less developed countries.

The contribution of income growth to the mortality decline is reported in Table 13 . The table shows information for all age groups and for infectious diseases according to sensitivity to nutrition. The results confirm the importance of income growth for the mortality decline during the second half of the 20th century. Between one-third and one-half of the gains in mortality at the youngest ages can be related to the increase in income. The estimates based on the two cross-sections tend to be higher than the estimated contribution that results if the coefficients from the dynamic panel estimates are employed. The estimates for the sample of less developed countries are also below the estimated contribution from the world sample, but even if those coefficients are employed, an average of $30 \%$ of the ASDR decline can be related to changes in income.

Table 13 also shows that the contribution of economic development as measured by income per capita differs by cause of death, but is larger for the diseases sensitive to nutritional status. For those conditions, the contribution of income is larger than for diseases that have minimal sensitivity to nutrition. Based on the estimates from Table 9 or on the cross-sectional estimates, the average contribution of income growth to the decline of diseases sensitive to nutrition is $45 \%$.

\section{CONCLUSIONS}

Over the course of the last 300 years, the world has experienced the most pronounced population increase in human history. The increase in population has occurred in spite of an unprecedented fertility decline because the decline in mortality has outpaced the decline in fertility in every country in the world. Although this increase in population is often interpreted as driven by exogenous forces, this paper shows that an important component of the escape from high mortality can be associated with economic development. This is perhaps better illustrated in the statistical decomposition provided in the paper. And while the contribution of economic development is non-trivial and apparently not smaller than in previous studies (i.e., Preston, 1975, 1980, 1985), the paper does not define the factors that are operative in the mortality decline, and that certainly is the biggest limitation of the study. Income changes due to better nutrition, public health, and education are obvious possibilities.

Still, our results support the view that agricultural changes associated with economic development initiated the escape from high mortality and provided the conditions for higher population and higher income in the world. As food availability increased, anthropometric and epidemiological evidences indicate that people in developed countries became taller, heavier, and less susceptible to infectious diseases, especially to diseases in which nutritional status has a definite influence. Since it is not possible to track significant public health changes to rural areas in developed countries before 1920 (see, e.g., Higgs, 1973), most of the initial gains in nutritional status have to be attributed to improvements in the diet or in the number of calories available.

Public health measures such as pasteurization of milk, water purification, sanitary sewer disposal, and many others (see Easterlin, 2004 for a summary) had a large impact on reducing mortality, but they were almost exclusively urban phenomena in developed countries in the initial stages. And while mortality in cities declined drastically due to health interventions (see Cutler \& Miller, 2005), mortality in cities started to decline once death rates in rural areas were already declining. Incidentally, cities also displayed relatively low fertility, so modern urban centers could only be expanded by a constant influx of immigrants from rural areas. 
Higher population in rural areas could only emerge by higher fertility and/or lower mortality, both closely related to the transformation of agriculture.

Unquestionably, sanitation proved successful after the advent of the germ theory of disease, benefiting developed countries at the beginning of the 20th century but mainly allowing less developed countries to avoid the urban penalty in mortality. In less developed countries, the mortality gradient favors cities and not rural areas. The reversal of the urban penalty is undoubtedly the major qualitative difference that characterizes the historical experience of developed countries and the contemporary mortality decline in less developed countries.

Economic and population growth in less developed countries has also been faster than in developed countries, but the mortality decline in less developed countries shares important similarities with the escape from high mortality of developed countries, as we show in this paper. In both cases, the decline in mortality corresponds to an epidemiological transition that reduced infectious disease mortality, especially child mortality. There are multiple channels through which economic development reduced infectious disease mortality, but, as expected, the effect of income per capita is larger for infectious diseases sensitive to nutritional status. According to our estimates, the contribution of per capita income to the world mortality decline from diseases sensitive to nutrition can be as large as $45 \%$. The contribution to the overall mortality decline and to the decline of all infectious diseases is close to $30 \%$.

\section{NOTES}

1. The introduction of smallpox vaccination is reported to have contributed to the initial decline in child mortality, although the effects are not uniform or sufficiently big to be a major contribution; see Bengtsson (1998). Also, the continuing decline in the annual death rate from smallpox in England was disrupted immediately after smallpox vaccination laws were enforced (McKeown, 1976).

2. Many volumes have studied the role of different factors in the decline of mortality in developed countries. McKeown (1976) first suggested that improvements in nutrition were the main reason for the decline of mortality. Mercer (1990) focused primarily on smallpox vaccinations; Livi-Bacci (1991) suggests that nutrition has not had a decisive role in the long-term decline aside from short-term effects. Fridlizius (1984) focuses on balance changes between pathogens and human hosts. Several aspects of the debate have been reviewed in Bengtsson (1998), Fogel (1997), and Kunitz (1986), among many others.

3. In support of rapid genetic changes in humans, Galor and Moav (2002, 2004) offer evidence from melanism in peppered moths. Since the reproductive strategy of insects and small animals is, in general, at an advantage in rapidly changing environments, these animal's genetic response cannot be extrapolated to humans, who are at an advantage in stable environments (Relethford, 1996). Galor and Moav (2002, 2004) also consider lactose and gluten tolerance and the sickle cell trait as examples of mutations in humans but they hardly seem relevant for modern mortality and population change, especially since African populations, having a genetic advantage for low mortality, still experience the lowest life expectancies in the world.

4. The mortality decline and the contribution of infectious diseases have often been interpreted in terms of the epidemiologic transition described by Omran (1971). This particular variant of the demographic transition recognizes the fundamental role of infection in modern population dynamics.

5. We focus in England and Wales due to data availability. The main difference with most developed countries is that fertility increased in 18th-century England more than in Sweden and France, as Wrigley and Schofield (1981) have documented. A decline in fertility followed the decline in mortality as in all countries in the world. This is important because the idea that mortality declined after fertility is often used to argue against the role of mortality for a demographic transition (see Doepke, 2005). From pure arithmetic reasoning, if a fertility decline is not preceded by a corresponding decline in mortality, population growth would decline rather than increase as in all demographic transitions.

6. The initial date of the mortality decline is somewhat difficult to define because the time series of life expectancy at birth show considerable (yet erratic) improvement since the second quarter of the 18th century (Wrigley et al., 1997, Figure 6.17). By the 1720s, however, life expectancy was at its second lowest point since 1600 . Infant and child mortality only started its decline after 1750 . 
7. Mortality rates for Sweden (Keyfitz \& Flieger, 1986), the only country with official 18th century data, and reconstructions for France (Vallin, 1991) show a similar figure. In 1780, child mortality in Sweden was 30\% but was virtually eliminated by the middle of the 20th century. For the period 1740-49, the chance of a child dying during the first five years of life in France was $47.4 \%$.

8. Boucekkine, de la Croix, and Licandro (2003) argue that mortality for the working age population declined before child mortality and served as an incentive for human capital accumulation and long-term economic growth. However, their analysis uses data for Geneva and Venice, so generalizations and extrapolations are difficult. In England and Wales, substantial improvements in adult mortality took place during the first half of the 18th century, but they were largely offset until the 1750s (Wrigley et al., 1997, p. 298).

9. Woods (2000, chap. 9) expresses some caution on the generalizations of Szreter and Mooney (1998), but confirms the overall trend. Anthropometric evidence corroborates the urban penalty, but the analysis of heights will be considered below. During the 18th century, city dwellers were shorter than the inhabitants of rural areas of England, according to Floud, Wachter, and Gregory (1990). The analysis of Japan, China, and other non-European regions, however, has not provided a uniform confirmation of the urban penalty, although there is large uncertainty in the available information (Woods, 2003).

10. Height also declined markedly during 1820-60 in adult males born in the fast-growing industrial cities in the United States (Margo \& Steckel, 1983) and Europe (Floud et al., 1990). Komlos (1993) argues that the decline in height started as early as 1750 . Haines (2004) and Komlos (1998) provide recent overviews of the "antebellum puzzle," which denotes the decline in heights with industrialization in developed countries. Obviously, the reduction in heights is a puzzle only to the extent that it is not accounted for by the change in the disease environment.

11. Lagerlöf (2003) presents a model that links mortality crises to human capital accumulation and early economic growth. He correctly points out that crises receded in continental Europe and Scandinavia much after than in England and Wales. However, crises were concentrated in space and time so their aggregate impact on mortality was small.

12. The Irish potato famine represents one important exception of pre-modern famines. In a population of 8.5 million in 1845 , the Irish potato famine caused approx- imately 1.2 million deaths before 1851 , forced 2.1 million people to migrate before 1855 , and forced an additional 3 million to migrate during the subsequent five years. Even at the end of the 20th century, the population of Ireland remained below the pre-famine level (O'Gráda, 1994).

13. Harris (2004) provides a recent overview of the role of nutrition and public health in the mortality decline of England and Wales with detailed accounts of the trends in wages, earnings, food availability, and changes in the disease environment.

14. Most of the analyses of heights are restricted to males due to data availability. When samples for females are analyzed, the data tend to show that women's height declined prior to males (Komlos \& Baten, 2004, p. 202). Baten and Murray (2000) find, through 19th-century Bavarian prison records, that women's height is more responsive to crises than men's. Similar effects are found in modern poor countries (see Dercon \& Krishnan, 2000).

15. Early ages are also crucial for determining final height. Baten and Murray (2000) find that food intakes during the first year of life have the strongest influence on final adult stature.

16. According to Landers (1992), dysentery, diarrhea, and non-respiratory tuberculosis peak in the summer; typhus, respiratory tuberculosis, and bronchitis typically peak in the winter, while diphtheria, typhoid, and scarlet fever peak in the fall.

17. According to the World Bank (2000), low income countries in the year 2000 had a life expectancy at birth of 58.9 years and an infant mortality rate of 76 . England and Wales only achieved similar levels during the 20th century, when the mortality decline was already in progress.

18. Sen (1981) suggested that low food availability is not a pre-condition for famines since food crises are more a consequence of inadequate distribution of food to low income groups. Ravallion (1997) summarizes the more relevant aspects of the economic analysis of famines. Dyson and O'Gráda (2002) present case studies on the demography of famines.

19. Young (2004) suggests that the epidemic will increase the future per capita consumption possibilities of the survivors due to the diminishing returns to scale that population has on production. Young (2004) also serves to confirm how bad income per capita is as a measure of the standard of living. 
20. Inferences from household surveys in less developed countries consistently show the adverse effects of inadequate nutrition on premature mortality and morbidity (Behrman \& Deolalikar, 1988; Ravallion, 1987).

21. Anand and Ravallion (1993) consider an additional decomposition to measure the effects of public health. According to them, two-thirds of the correlation between income and mortality in less developed countries is due to public health investments and the remaining one-third to low incomes or poverty.

22. The WHOSIS Mortality Database also contains supplementary population data to calculate mortality rates. Age standardization is done with the WHO standard population. The database contains 3,649 countries-years of data totalling more than 2 million records.

23. Becker et al. (2005) argue that exogenous changes are the main factor in the mortality reduction from respiratory conditions. However, as Preston (1980, p. 313 ) notes: "No effective preventive measure has been deployed against these diseases [influenza/pneumonia/ bronchitis], the effectiveness of immunization being minimal, and there are suggestions that antibiotics, sulfa drugs, and curative services are not widely enough available in LDCs to have substantially altered the disease picture."

24. Baltagi and Griffin (1988) include an additional term $\lambda_{j}\left[\ln \left(y_{i t}\right) A_{j}(t)\right]$. Given the estimates of the parameters, the hypothesis of an increasing role for technological change in mortality can be tested by a joint test of $\lambda_{j}=0$ since $\lambda_{j} \ln \left(y_{i t}\right) A_{j}(t)$ gives a form of scale augmentation. We omit this interaction term.

25. Lagged values serve as adequate instruments if income levels have much stronger (and longer) serial correlation than death rates. The adequate estimator, however, depends on assumptions about the memory of income and mortality, the sample size, and on whether the instruments are uncorrelated with the country effects (see Arellano \& Bond, 1991).

26. The output of the cross-sectional estimates is not reported, but it is available upon request. The (unreported) cross-sectional response of mortality to income declined during 1960s-90s as Preston (1975) first noticed for world data during 1930s-60s.

\section{REFERENCES}

Anand, S., \& Ravallion, M. (1993). Human development in poor countries: on the role of private incomes and public services. Journal of Economic Perspectives, 7, $133-150$.

Arellano, M., \& Bond, S. (1991). Some tests of specification for panel data: Monte Carlo evidence and an application to employment equations. Review of Economic Studies, 58, 277-297.

Arriaga, E. (1968). New life tables for Latin American populations in the nineteenth and twentieth centuries. Institute of International Studies.

Baltagi, B. H., \& Griffin, J. M. (1988). A general index of technical change. Journal of Political Economy, 96, $20-41$.

Baten, J. (2000-01). Height and real wages: an international comparison. Jahrbuch fuer Wirtschaftsgeschichte, 61-76.

Baten, J. (2002). Climate, grain production and nutritional status in 18th century Southern Germany. Journal of European Economic History, 30, 9-47.

Baten, J., \& Fertig, G. (2005). After the Railway Came: Was the health of your children declining? A hierarchical mixed models analysis of German heights. Mimeo, University of Tuebingen.

Baten, J., \& Murray, J. (2000). Heights of men and women in nineteenth century Bavaria: economic, nutritional, and disease influences. Explorations in Economic History, 37, 351-369.

Becker, G., Philipson, T. J., \& Soares, R. R. (2005). The quantity and quality of life and the evolution of world inequality. American Economic Review, 95, 277-291.

Behrman, A., \& Deolalikar (1988). Health and nutrition. In H. Chenery, \& T. N. Srinivasan (Eds.). Handbook of development economics (Vol. 1, pp. 647-679). North Holland.

Bengtsson, T. (1998). The great mortality decline: its causes and consequences. In C. Núñez, (Ed.), Debates and controversies in economic history (pp. 1080-1085).

Blundell, R. W., \& Bond, S. R. (1998). Initial conditions and moment restrictions in dynamic panel data models. Journal of Econometrics, 87, 115-143.

Boucekkine, R., de la Croix, D., \& Licandro, O. (2003). Early mortality declines at the dawn of modern growth. Scandinavian Journal of Economics, 105, 401-418.

Bourguignon, F., \& Morrison, C. (2002). Inequality among world citizens. American Economic Review, 92, 727-744.

Brockerhoff, M., \& Brenna, E. (1998). The poverty of cities in developing regions. Population and Development Review, 24, 75-113.

Case, R. A. M., Coghill, C., Harley, J. L., \& Pearson, J. (1962). The Chester Beatty Research Institute serial abridged life tables: England and Wales, 1841-1960. Chester Beatty Research Institute.

Conferees (1983). The relation of nutrition, disease, and social conditions: a graphical representation. Journal of Interdisciplinary History, 14, 503-506. 
Cutler, D., \& Miller, G. (2005). The role of public health improvements in health advances: the twentiethcentury United States. Demography, 42, 1-22.

Dercon, S., \& Krishnan, P. (2000). In sickness and in health: risk sharing within households in rural Ethiopia. Journal of Political Economy, 108, 688-727.

Doepke, M. (2005). Child mortality and fertility decline: does the Barro-Becker model fit the facts? Journal of Population Economics, 18, 337-366.

Dyson, T., \& O'Gráda, C. (2002). Famine demography. Perspectives from the past and present. Oxford University Press.

Easterlin, R. A. (2004). The reluctant economist: Perspectives on economics, economic history, and demography. Cambridge University Press.

Easterly, W. (1999). Life during growth. Journal of Economic Growth, 4, 239-275.

Elo, I., \& Preston, S. (1992). Effects of early-life conditions on adult mortality: a review. Population Index, 58, 186-212.

Floud, R., Wachter, K., \& Gregory, A. (1990). Height, health, and history: Nutritional status in the United Kingdom, 1750-1980. Cambridge University Press.

Fogel, R. (1992). Second thoughts on the European escape from hunger: famines, chronic malnutrition, and mortality rates. In S. Osmani (Ed.), Nutrition and poverty (pp. 243-286). Oxford University Press.

Fogel, R. (1994). Economic growth, population theory, and physiology: the bearing of long-term processes on the making of economic policy. American Economic Review, 84, 369-395.

Fogel, R. (1997). New findings on secular trends in population and mortality. In M. Rosenzweig, \& O. Stark (Eds.), Handbook of population and family economics (pp. 434-481). North Holland.

Fogel, R., Engerman, S., Trussell, J., Floud, R., \& Pope, C. (1978). The economics of mortality in North America, 1650-1910: a description of a research project. Historical Methods, 11, 75-108.

Fridlizius, G. (1984). The mortality decline in the first phase of the demographic transition: Swedish experiences. In T. Bengtsson, G. Fridlizius, \& R. Ohlsson (Eds.), Pre-Industrial population change (pp. 71-114). Almquist and Wiksell.

Galor, O., \& Moav, O. (2002). On natural selection and the origin of modern economic growth. Quarterly Journal of Economics, 117, 1133-1191.

Galor, O. \& Moav, O. (2004). Natural selection and the evolution of life expectancy. Mimeo, Brown University.

Haines, M. (2001). The urban mortality transition in the United States, 1800-1940. Annales de Demographie Historique, 1, 33-64.

Haines, M. (2004). Growing incomes, shrinking people-can economic development be hazardous to your health?. Social Science History, 28, 249-270.

Harris, B. (2004). Public health, nutrition and the decline of mortality: the McKeown thesis revisited. Social History of Medicine, 17, 379-407.

Hedenborg, S. (2000). The world is full of sorrow: infant mortality in Stockholm 1754-1850. Scandinavian Economic History Review, 48, 64-80.
Heston, A., Summers, R., \& Aten, B. (2002). Penn World Table Version 6.1. Center for International Comparisons at the University of Pennsylvania (CICUP).

Higgs, R. (1973). Mortality in rural America, 18701920: estimates and conjecture. Explorations in Economic History, 10, 177-195.

Huck, P. (1997). Shifts in the seasonality of infant deaths in nine English towns during the nineteenth century: a case for reduced breast feeding? Explorations in Economic History, 34, 368-386.

Jones, R. (1980). Further evidence on the decline in infant mortality in pre-industrial England: North Shropshire, 1561-1810. Population Studies, 34, 239-250.

Kalemli-Ozcan, S., Ryder, H. E., \& Weil, D. N. (2000). Mortality decline, human capital investment, and economic growth. Journal of Development Economics, 62, 1-23.

Keyfitz, N., \& Flieger, W. (1986). World population: An analysis of vital data. University of Chicago Press.

Köepke, N., \& Baten, J. (2005). The biological standard of living in Europe during the last two millennia. European Review of Economic History, 9, 61-95.

Komlos, J. (1993). The secular trend in the biological standard of living in the United Kingdom, 17301860. Economic History Review, 46, 115-144.

Komlos, J. (1998). Shrinking in a growing economy? The mystery of physical stature during the industrial revolution. Journal of Economic History, 58, 779-802.

Komlos, J. (2006). On British pygmies and giants: the physical stature of British youth in the 18th and 19th centuries. Mimeo, University of Munich.

Komlos, J., \& Baten, J. (2004). Looking backward and looking forward: anthropometric research and the development of social science history. Social Science History, 28, 191-210.

Komlos, J., \& Cinnirella, F. (2005). European heights in the early 18 th century. Mimeo, University of Munich.

Kunitz, S. (1983). Speculations on the European mortality decline. Economic History Review, 36, 349-364.

Kunitz, S. (1986). Mortality since Malthus. In D. Coleman, \& R. Schofield (Eds.), The state of population theory: Forward from Malthus (pp. 279-302). Blackwell.

Lagerlöf, N.-P. (2003). From Malthus to modern growth: can epidemics explain the three regimes? International Economic Review, 44, 755-777.

Landers, J. (1992). Historical epidemiology and the structural analysis of mortality. Health Transition Review, 2, 47-75.

Livi-Bacci, M. (1991). Population and nutrition. An essay on European demographic history. Cambridge University Press.

Lunn, P. (1991). Nutrition, immunity and infection. In R. Schofield, D. Reher, \& A. Bideau (Eds.), The decline of mortality in Europe (pp. 131-145). Clarendon Press.

Malaker, C. R., \& Roy, G. (1990). Reconstruction of Indian life tables for 1901-1981 and projections for 
1981-2001. Sankhyā: The Indian Journal of Statistics, $52,271-286$.

Malthus, T. (1803, [1998]). An essay on the principle of population, Amherst.

Margo, R., \& Steckel, R. (1983). Heights of native born Northern Whites during the Antebellum period. Journal of Economic History, 43, 167-174.

McKeown, T. (1976). The modern rise of population. Edward Arnold.

Meltzer, D. (1992). Mortality decline, the demographic transition, and economic growth. Ph.D. Dissertation, Department of Economics, University of Chicago.

Mercer, A. (1990). Disease mortality and population in transition. Leicester University Press.

Miguel, E., \& Kremer, M. (2004). Worms: identifying impacts on education and health in the presence of treatment externalities. Econometrica, 72, 159-217.

Moradi, A., \& Baten, J. (2005). Inequality in subSaharan Africa: new data and new insights from anthropometric estimates. World Development, 33, 1233-1265.

Mosley, W. H., \& Gray, R. (1993). Childhood precursors of adult morbidity and mortality in developing countries: implications for health programs. In J. Gribble, \& S. Preston (Eds.), The epidemiological transition: Policy and planning implications for developing countries (pp. 69-100). Washington: National Academy Press.

Oaxaca, R., \& Ransom, M. (1994). On discrimination and the decomposition of wage differentials. Journal of Econometrics, 61, 5-21.

Oeppen, J., \& Vaupel, J. W. (2002). Broken limits to life expectancy. Science, 296(5570), 1029-1031.

O'Gráda, C. (1994). Ireland: a new economic history 1780-1939. Oxford Clarendon Press.

Omran, A. (1971). The epidemiologic transition: a theory of the epidemiology of population change. Milbank Memorial Fund Quarterly, 29, 509-538.

Osmani, S. (1998). Famine, demography, and endemic poverty. In M. Livi-Bacci, \& G. De Santis (Eds.), Population and poverty in the developing word (pp. 61-83). Oxford University Press.

Preston, S. (1975). The changing relation between mortality and level of economic development. Population Studies, 29, 231-248.

Preston, S. (1980). Causes and consequences of mortality change in less developed countries in the twentieth century. In R. Easterlin (Ed.), Population and economic change in developing countries (pp. 289-360). University of Chicago Press.

Preston, S. (1985). Mortality and development revisited. Population Bulletin of the United Nations, 18, $34-40$.

Preston, S., \& Van de Walle, E. (1978). Urban French mortality in the nineteenth century. Population Studies, 32, 275-297.

Pritchett, L., \& Summers, L. (1996). Wealthier is healthier. Journal of Human Resources, 31, 841-868.

Ravallion, M. (1987). Markets and famines. Oxford University Press.

Ravallion, M. (1997). Famines and economics. Journal of Economic Literature, 35, 1205-1242.
Relethford, J. (1996). The human species. Mayfiled Publishing Company.

Roodman, D. (2003). XTABOND2: Stata Module to Extend xtabond Dynamic Panel Data Estimator. Statistical Software Components S435901.

Scheidel, W. (1994). Libitina's bitter gains: seasonal mortality and endemic disease in the ancient city of Rome. Ancient Society, 25, 151-175.

Scrimshaw, N. S., Taylor, C. E., \& Gordon, J. E. (1968). Interactions of nutrition and infection. Geneva: World Health Organization.

Sen, A. (1981). Poverty and famines, an essay on entitlement and deprivation. Oxford University Press.

Steckel, R. (2005a). Health and nutrition in the preindustrial era: insights from a millennium of average heights in Northern Europe. In R. C. Allen, T. Bengstsson, \& M. Dribe (Eds.), Living standards in the past: New perspectives on well-being in Asia and Europe. Oxford University Press.

Steckel, R. H. (2005b). Health and nutrition in preColumbian America: the skeletal evidence. Journal of Interdisciplinary History, 36, 1-32.

Szreter, S., \& Mooney, G. (1998). Urbanization, mortality, and the standard of living debate: new estimates of the expectation of life at birth in nineteenth-century British cities. Economic History Review, 51, 84-112.

Turpeinen, O. (1978). Infectious diseases and regional differences in Finnish death rates, 1749-1773. Population Studies, 32, 523-533.

United Nations (several years). Demographic yearbook. United Nations.

Vallin, J. (1991). Mortality in Europe from 1720 to 1914: long-term trends and changes in patterns by age and sex. In R. Schofield, D. Reher, \& A. Bideau (Eds.), The decline of mortality in Europe (pp. 38-67). Clarendon Press.

Weir, D. (1997). Economic welfare and physical wellbeing in France, 1750-1990. In R. Floud, \& R. Steckel (Eds.), Health and welfare during industrialization. University of Chicago Press.

Weir, D. R. (1993). Parental consumption decisions and child health during the early French fertility decline, 1790-1914. Journal of Economic History, 53, 259-274.

Williams, N., \& Galley, C. (1995). Urban-rural differentials in infant mortality in Victorian England. Population Studies, 49, 401-420.

Woods, R. (2000). The demography of Victorian England and Wales. Cambridge University Press.

Woods, R. (2003). Urban-rural mortality differentials: an unresolved debate. Population and Development Review, 29, 29-46.

World Bank (2000). World Development Indicators Database. $<$ http://devdata.worldbank.org/data-query/>.

WHO Statistical Information System (WHOSIS). $<$ http://www.who.int/whosis/>.

Wrigley, E. (1987). People, cities and wealth. Oxford Blackwell.

Wrigley, E., Davis, R., Oeppen, J., \& Schofield, R. (1997). English population history from family reconstruction, 1580-1837. Cambridge University Press. 
Wrigley, E., \& Schofield, R. (1981). The population history of England 1541-1871: A reconstruction. Edward Arnold.

Young, A. (2004). The gift of the dying: the tragedy of AIDS and the welfare of future African generations. Quarterly Journal of Economics, 120, 423-466.

\section{APPENDIX A. ICD CODING}

See Table A1.

Table A1. ICD classification of causes of death

\begin{tabular}{|c|c|c|c|c|}
\hline Disease group & ICD7 A & ICD8 A & ICD9 B & ICD10 \\
\hline All causes & A000 & A000 & B000 & AAA \\
\hline $\begin{array}{l}\text { Respiratory } \\
\text { tuberculosis }\end{array}$ & A001 & A006 & B020-B021 & A15-A16 \\
\hline $\begin{array}{l}\text { Non-respiratory } \\
\text { tuberculosis }\end{array}$ & A002-A005 & A007-A010 & B022-B025, B077 & A17-A19 \\
\hline Typhoid fever & A012 & A002 & B011 & A01 \\
\hline Cholera & A014 & A001 & B010 & A00 \\
\hline Dysentery & A016 & A004 & B012 & A03 \\
\hline Scarlet fever & A017 & A017 & B035 & A38 \\
\hline Diphtheria & A021 & A015 & B033 & A36 \\
\hline Whooping cough & A022 & A016 & B034 & A37 \\
\hline Meningococcal inf. & A023 & A019 & B036 & A39 \\
\hline Plague & A024 & A011 & B030 & A20 \\
\hline Poliomyelitis & A028 & A022, A023 & B040 & A 80 \\
\hline Smallpox & A031 & A024 & B041 & B03 \\
\hline Measles & A032 & A025 & B042 & B05 \\
\hline Typhus & A036 & A030 & B050, B051 & A75 \\
\hline Malaria & A037 & A031 & B052 & B50-B54 \\
\hline $\begin{array}{l}\text { Other infectious } \\
\text { diseases }\end{array}$ & $\begin{array}{l}\text { A006-A011, A013, } \\
\text { A015, A018-A020, } \\
\text { A025-A027, A029, } \\
\text { A030, A033-A035, } \\
\text { A038-A043 }\end{array}$ & $\begin{array}{c}\text { A003, A005, } \\
\text { A012-A014, } \\
\text { A018, A020, } \\
\text { A021, A026-A029, } \\
\text { A032-A044 }\end{array}$ & $\begin{array}{c}\text { В013-B016, В019, } \\
\text { В029, В031, В032, } \\
\text { В037-B039, В043- } \\
\text { B049, В053, В054, } \\
\text { В059, В06-B07 }\end{array}$ & $\begin{array}{c}\text { A02, A04-A09, A21-A35, } \\
\text { A40-A74, A76-A79, } \\
\text { A81-A99, B01, B02, } \\
\text { B04, B06-B49, B55-B99 }\end{array}$ \\
\hline
\end{tabular}

Available online at www.sciencedirect.com 